\title{
HYBRID GAS BEARINGS WITH CONTROLLED SUPPLY PRESSURE TO ELIMINATE ROTOR VIBRATIONS WHILE CROSSING SYSTEM CRITICAL SPEEDS
}

\author{
A Thesis \\ by \\ KEUN RYU \\ Submitted to the Office of Graduate Studies of \\ Texas A\&M University \\ in partial fulfillment of the requirements for the degree of \\ MASTER OF SCIENCE
}

August 2007

Major Subject: Mechanical Engineering 


\title{
HYBRID GAS BEARINGS WITH CONTROLLED SUPPLY \\ PRESSURE TO ELIMINATE ROTOR VIBRATIONS WHILE \\ CROSSING SYSTEM CRITICAL SPEEDS
}

\author{
A Thesis \\ by \\ KEUN RYU \\ Submitted to the Office of Graduate Studies of \\ Texas A\&M University \\ in partial fulfillment of the requirements for the degree of \\ MASTER OF SCIENCE
}

Approved by:

Chair of Committee, Luis San Andrés

Committee Members, Alan B. Palazzolo

Luciana R. Barroso

Head of Department, Dennis L. O'Neal

August 2007

Major Subject: Mechanical Engineering 


\author{
ABSTRACT \\ Hybrid Gas Bearings with Controlled Supply Pressure to Eliminate Rotor Vibrations \\ While Crossing System Critical Speeds. (August 2007) \\ Keun Ryu, B.S., Hanyang University; \\ M.S., Hanyang University \\ Chair of Advisory Committee: Dr. Luis San Andrés
}

Micro-turbomachinery (MTM) implements gas bearings in compact units of enhanced mechanical reliability. Gas bearings, however, have little damping and are prone to wear during frequent rotor start-up and shut down conditions. Externally pressurized gas bearings provide a simple solution to overcome excessive drag and allowing rub-free operation during transient response events. Some commercial MTM currently implements gas foil bearings, a costly proprietary technology with few, if any, proven reliable predictive design models. The thrust of this research is to investigate conventional bearings of low cost, easy to manufacture (common materials) and easy to install and align.

Flexure pivot tilting pad bearings offer little or no cross-coupled stiffnesses with enhanced rotordynamic stability. These bearings, modified for hydrostatic pressurization, demonstrated superior rotordynamic performance over other simple gas bearing configurations. The test rig comprises of a rigid rotor, $0.825 \mathrm{~kg}$ and $28.6 \mathrm{~mm}$ in diameter, supported on two hybrid flexure pivot hybrid gas bearings, each with four pads and $60 \%$ pivot offset and $0.6 \mathrm{~mm}$ feeding holes. Experimental results show that external pressurization stiffens the gas bearings, increasing the system critical speed while reducing the modal damping. Most importantly, the tests demonstrate that external pressurization is not needed for super critical speed operation. In practice, the supply pressure could be shut off at high speeds with substantial savings in operational efficiency. In addition, controlling the feed pressure while the rotor passes through its 
critical speeds can eliminate high amplitude motions because of the bearings' inherent little damping.

In 2007, the test rig integrates an inexpensive automatic air pressure regulator to control the supply pressure into the gas bearings. The measured system dynamic response determines the regulator control scheme with a programmed schedule over a rotor speed region enclosing the system critical speeds. Rotor speed coast-down tests with controlled supply pressure into the bearings demonstrate the effective elimination of large rotor motion amplitudes while crossing the system critical speeds. The simple on-off supply pressure control, i.e. a sudden increase in pressure while approaching a critical speed, is the best since it changes abruptly the bearing stiffness coefficients and moves the system critical speed to a higher speed.

A rotordynamic analysis, integrating bearing force coefficients predicted by an existing TRC computational model, forwards critical speeds in agreement with the test results. Predicted rotor synchronous responses for the cases with controlled supply show an excellent correlation with the measured responses. The experiments validate the predictive tools and demonstrate the controllable rotordynamic characteristics of the flexure pivot hybrid gas bearings. 


\section{DEDICATION}

This thesis is dedicated

To God, who is rich in mercy and love

To my lovely wife, Dong Yun Lee, for her love, prayer, and company

To my father and mother, for their love, guidance, and support

To my brother, Hoon, for his love and encouragement

To my home country, Korea 


\section{ACKNOWLEDGEMENTS}

I would like to thank my adviser, Dr. Luis San Andrés, for providing the environment which made all of this work possible. His encouragement, advice, and guidance are gratefully appreciated.

I would like to thank my thesis committee members, Dr. Alan B. Palazzolo and Dr. Luciana R. Barroso, for their time and effort in offering advice.

The support of the Turbomachinery Research Consortium (TRC) is also gratefully acknowledged.

I would like to thank my former and current colleagues and friends at the Turbomachinery Lab., Tae Ho Kim, Nick Tydlacka, Anthony Breedlove, Chad Jarrett, Adolfo Delgado, Jose Baker, Ash Maruyama, Michael Forsberg, Fernando Ramirez, Christina Twist, Juan Carlos Valles, Clint Carter, Henry Borchard, B. J. Dyck. I would especially like to thank Adolfo Delgado and Tae Ho Kim for their help and advice on my work and for their friendship. I also would like to thank Mr. Eddie Denk for his assistance.

I would like to thank Dr. Yong-Bok Lee and Dr. Chang-Ho Kim, who were my adviser at Korea Institute of Science and Technology, and Dr. Gunhee Jang, who was my adviser at Hanyang University, for their mentorship and encouragement.

I would like to thank my family for their love and prayers.

Thank you, Lord. You gave me the strength and made a way for me. "The LORD is my shepherd, I shall not be in want. He makes me lie down in green pastures, he leads me beside quiet waters... Surely goodness and love will follow me all the days of my life, and I will dwell in the house of the LORD forever.- Psalm 23-" 


\section{NOMENCLATURE}

$A_{u} \quad$ Peak-to-peak amplitude of unfiltered rotor vibration [m]

$C_{b} \quad$ Radial bearing clearance [m]

$C_{i, j} \quad$ Bearing damping coefficients; $i, j=X, Y[\mathrm{~N}-\mathrm{s} / \mathrm{m}]$

$C_{p} \quad$ Radial pad clearance [m]

$d_{o} \quad$ Feed orifice diameter [m]

$D_{b} \quad$ Bearing diameter [m]

$D_{j} \quad$ Rotor Diameter [m]

$e \quad$ Journal eccentricity [m]

$I_{p} \quad$ Pad mass moment of Inertia $\left[\mathrm{kg}-\mathrm{m}^{2}\right]$

$K_{i, j} \quad$ Bearing stiffness coefficients; $i, j=X, Y[\mathrm{~N} / \mathrm{m}]$

$K_{\delta \delta} \quad$ Web rotational stiffness [Nm/rad]

$L \quad$ Bearing axial length [mm]

$M \quad$ Rotor mass [kg]

$N \quad$ Rotor speed [rev/min]

$P_{s} \quad$ Supply pressure (absolute) [bar]

$R_{p} \quad$ Pad radius [m]

$R_{j} \quad$ Rotor radius [m]

$X, Y \quad$ Inertial coordinate system

$\Omega \quad$ Angular frequency [Hz]

Acronyms

MTM Micro Turbo Machinery

TM Turbo Machinery 


\section{TABLE OF CONTENTS}

Page

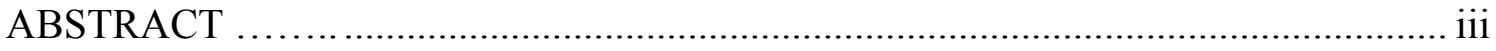

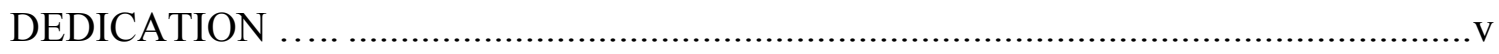

ACKNOWLEDGEMENTS ............................................................................ vi

NOMENCLATURE ...................................................................................... vii

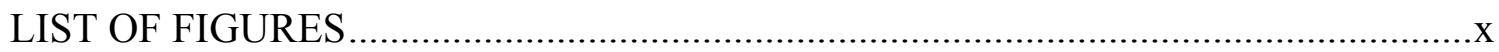

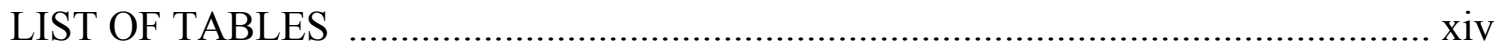

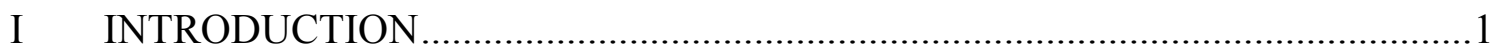

II LITERATURE REVIEW ........................................................................

III EXPERIMENTAL FACILITY ........................................................... 10

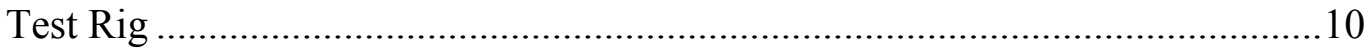

Test Rotor and Bearings ........................................................................... 11

Electronic Air Regulator and Tachometer for Supply Pressure Control System.15

IV EXPERIMENTAL PROCEDURE ............................................................... 17

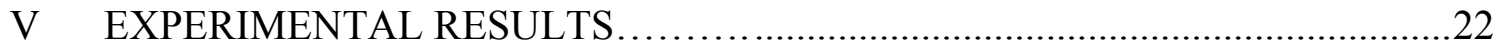

Determination of Control Speed Regime for Air Regulator .............................22

Estimation of Air Pressure Regulator Response Delay for Test System .............24

Measured Rotor Response Amplitudes for Each Operating Configuration ..........25

VI PREDICTIONS OF ROTORDYNAMIC RESPONSE AND

COMPARISON TO TEST RESULTS

Comparison Between Predictions and Measured Imbalance Responses .............35

Imbalance Responses for Fixed Supply Pressures ..........................................35

Predicted Rotor Responses for Cases with Controlled Supply Pressures .......38

VIII CONCLUSIONS AND RECOMMENDATIONS .........................................42 


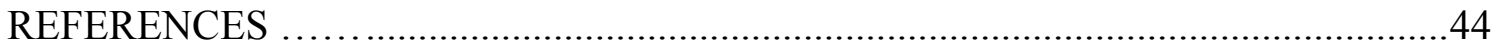

APPENDIX A PREDICTED BEARING STIFFNESS AND DAMPING FORCE COEFFICIENTS

APPENDIX B SPECIFICATIONS OF ELECTRO-PNEUMATIC AIR

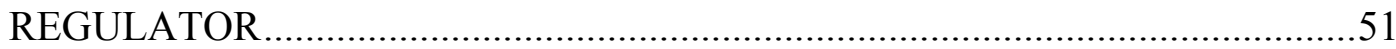

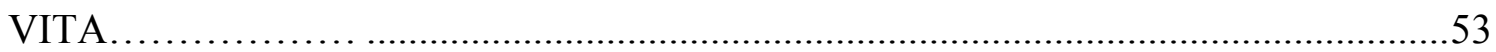




\section{LIST OF FIGURES}

Page

Figure 1 Photograph of flexure pivot-tilting pad gas bearing

Figure 2 Effect of increasing supply pressure on synchronous response of test rotor. Baseline imbalance. Right bearing vertical direction (RV). Taken from Ref. [10]

Figure 3 Layout of gas bearing test rig and instrumentation.

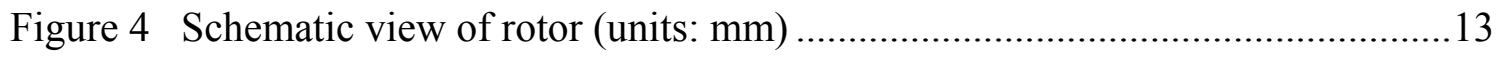

Figure 5 Drawing of test flexure pivot gas bearing (unit: $\mathrm{mm}$ ) ................................13

Figure 6 Estimated bearing radial clearances of left (L) and right (R) test bearings along horizontal $(\mathrm{H})$ and vertical $(\mathrm{V})$ directions. Approximate axial shape of pads.

Figure 7 Schematic view of air supply system with manual operation of adjustable pressure regulator. Open loop control. Operating conditions \#1 \#4.

Figure 8 Schematic view of automated air supply system with electronic air regulator. Closed loop control. Operating conditions \#5 \#8

Figure 9 Controlled supply pressure versus rotor speed for operating conditions $\# 2 \sim \# 8$

Figure 10 Increase of controlled supply pressure over a selected time span. Operating conditions \#2 and \#3

Figure 11 Synchronous rotor amplitudes versus rotor speed for three supply pressures. Right bearing horizontal direction ( $\mathrm{RH})$. Operating condition \#1 (constant pressure supply, rotor speed coast down)

Figure 12 Critical speed of test rotor-bearing system versus supply pressure into bearings. Right bearing horizontal direction $(\mathrm{RH})$. Operating condition \#1 (constant pressure supply, rotor speed coast down) 
Figure 13 Determination of $P_{s}$ control speed range. Right bearing horizontal direction (RH). Operating condition \#1 (constant pressure supply, rotor speed coast down)

Figure 14 Estimation of shaft speed change rate based on recorded coast down rotor speed versus time. 2.36 bar feed pressure. Operating condition \#1 (constant pressure supply, rotor speed coast down)

Figure 15 Rotor synchronous response versus shaft speed. Right bearing horizontal direction (RH). Operating conditions (O.C.) \#2 and 3. Manual pressure supply setting

Figure 16 Rotor synchronous response versus shaft speed. Right bearing horizontal direction (RH). Operating condition (O.C.) \#4. Step-wise manual pressure supply setting....

Figure 17 Rotor synchronous response versus shaft speed. Right bearing horizontal direction (RH). Operating conditions (O.C.) \#5 and 7. Controller activated system

Figure 18 Rotor synchronous response versus shaft speed. Right bearing horizontal direction (RH). Operating conditions (O.C.) \#6 and 8. Controller activated system.

Figure 19 Structural model of test rotor

Figure 20 Measured and predicted mass flow rates for test bearings versus supply pressure.....

Figure 21 Predicted damped natural frequency map of test rotor-bearing system. 5.08 bar feed pressure

Figure 22 Mode shapes of test rotor at critical speeds. 5.08 bar feed gas pressure.

Figure 23 Predicted damping ratios versus rotor speed for three feed pressures .35

Figure 24 Comparison of predicted and measured imbalance response of test rotor for supply pressure 5.08 bar (absolute) . Right bearing horizontal (RH) and left bearing horizontal (LH) directions 
Figure 25 Comparison of predicted and measured imbalance response of test rotor for increasing supply pressures. Right bearing horizontal direction (RH)......

Figure 26 Comparison of predicted and measured critical speeds of test rotorbearing system for increasing supply pressures along right bearing horizontal direction $(\mathrm{RH})$.

Figure 27 Predicted imbalance response for one-step increase in supply pressure (2.36 bar) at $14.2 \mathrm{krpm}$. Right bearing horizontal direction (RH).

Figure 28 Comparison of predicted and measured imbalance responses. Measurement for operating condition (O.C.) \#5 and prediction for onestep increase in supply pressure (2.36 bar) at $14.2 \mathrm{krpm}$. Right bearing horizontal direction $(\mathrm{RH})$

Figure 29 Predicted imbalance response for four-step increase of supply pressure (2.36 bar) from $13.9 \mathrm{krpm}$ to $13.0 \mathrm{krpm}$. Right bearing horizontal direction $(\mathrm{RH})$.

Figure 30 Comparison of predicted and measured imbalance responses.

Measurement for operating condition (O.C.) \#4 and prediction for fourstep increase in supply pressure $(2.36 \mathrm{bar})$ from $13.9 \mathrm{krpm}$ to $13.0 \mathrm{krpm}$. Right bearing horizontal direction (RH)

Figure 31 Predicted imbalance response for ramp increase in supply pressure $(2.36$ bar) from $14.2 \mathrm{krpm}$ to $13.0 \mathrm{krpm}$. Right bearing horizontal direction $(\mathrm{RH})$

Figure 32 Comparison of predicted and measured imbalance responses.

Measurement for operating condition (O.C.) \#6 and prediction for ramp increase in supply pressure (2.36 bar) from $14.2 \mathrm{krpm}$ to $13.0 \mathrm{krpm}$.

Right bearing horizontal direction (RH)

Figure A1 Predicted static journal eccentricity for step jump, multiple step-wise, and ramp increase in supply pressure. Static load $W=4.04 \mathrm{~N}$.

Figure A2 Predicted attitude angle for step jump, multiple step-wise, and ramp increase in supply pressure. Static load $W=4.04 \mathrm{~N}$. 
Figure A3 Predicted synchronous stiffnesses vs. speed. Right bearing. Step jump increase in supply pressure. Supply pressure increases at $14.2 \mathrm{krpm}$ from 2.36 bar to 5.08 bar (absolute)

Figure A4 Predicted synchronous damping coefficients vs. speed. Right bearing. Step jump increase in supply pressure. Supply pressure increases at 14.2 krpm from 2.36 bar to 5.08 bar (absolute)

Figure A5 Comparison of direct stiffnesses for step jump, multiple step-wise, and ramp increases in supply pressure. Synchronous speed coefficients. Right bearing horizontal direction.

Figure A6 Comparison of direct damping coefficients for step jump, multiple stepwise, and ramp increases insupply pressure. Synchronous speed coefficients. Right bearing horizontal direction .50

Figure B1 Photograph of electro-pneumatic air regulator 


\section{LIST OF TABLES}

Page

Table 1 Main parameters of test rotor and bearings ................................................ 15

Table 2 Summary of rotor speed and feed pressure conditions ................................20

Table 3 Representative clearance and preload for prediction of force coefficients

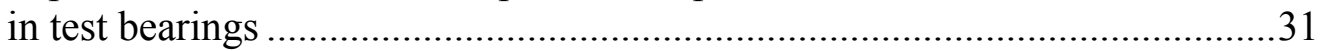

Table 4 Imbalance masses used for system response predictions ..............................36

Table B1 Main parameters of electro-pneumatic regulator...........................................52 


\section{INTRODUCTION}

Microturbomachinery (MTM), output power below $400 \mathrm{~kW}$, typically operates at high speeds and extreme temperatures and delivers reliable power in compact units of low weight. Gas bearings eliminate complex oil lubricating and sealing systems and reduce overall system length and weight [1]. Gas bearings also provide lower friction, less heat generation and power losses than oil-lubricated bearings [2]. Gas bearings thus provide many benefits, satisfy environmental restrictions, allow for extreme operating conditions [3], and even add value for those concerned with global warming.

Gas bearings, however, have low damping and load-carrying capacity due to the inherently small gas viscosity [4]. Consequently, gas bearings are not able to generate large enough hydrodynamic pressure fields to support applied (static or dynamic) loads during rotor start-up or shutdown events. Externally pressurized gas bearing configurations prevent transient rotor-bearing contact and reduce wear while at start up and shut down conditions [5].

Gas foil bearings are customarily used in air cycle machines, auxiliary power units, and commercial MTM because of their distinct advantages including tolerance to shaft misalignment and centrifugal/thermal growth, and large load capacity compared to rigid surface gas bearings [6]. However, the expensive development cost and lack of reliable analytical tools have limited universal application of foil bearings in larger TM.

Tilting pad bearings are widely used in high performance turbomachinery because of their inherent stability characteristics resulting from no generation of crosscoupled stiffness coefficients [7]. Flexure pivot tilting pad bearings, machined as a single piece using wire EDM (Electrical Discharge Machining) shown in Figure 1, provide the same rotordynamic advantages as tilting pad bearings. Flexure pivot tilting pad bearings eliminate pivot wear, contact stresses and pad flutter, and minimize the

This thesis follows the style of Journal of Engineering for Gas Turbines and Power. 
manufacturing tolerance stack-up [8]. Integrally machined pads with the bearing shell offer a compact unit, easier to install and maintain.

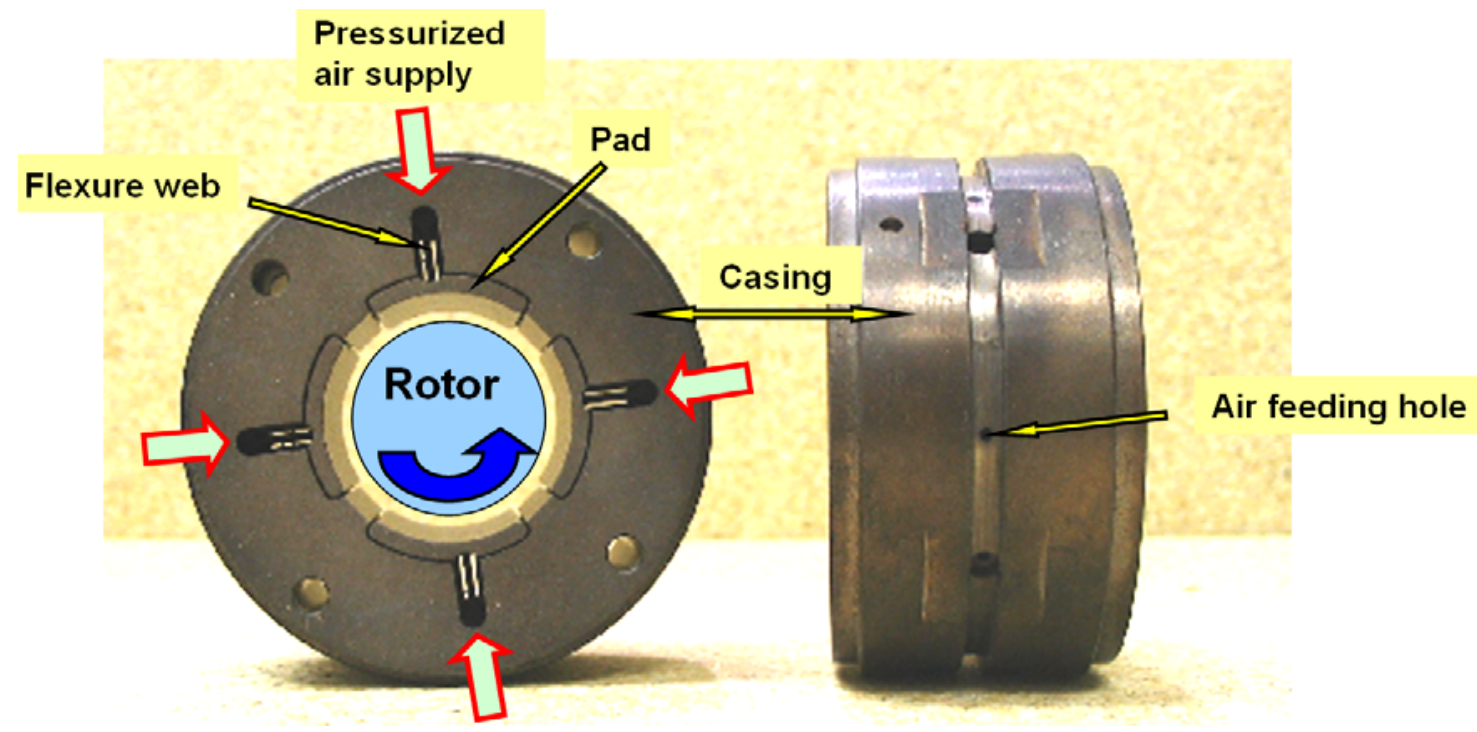

Fig. 1 Photograph of flexure pivot-tilting pad gas bearing.

Zhu and San Andrés [9] describe rotordynamic measurements of a high speed rotor supported on flexure pivot tilting pad gas hydrostatic bearings. Tests without supply pressure show the rotor becomes unstable at $\sim 81 \mathrm{krpm}$ with a whirl frequency ratio of $\sim 20 \%$. With external pressurization, the rotor-bearing system is stable to the top speed of the drive motor, $99 \mathrm{krpm}$. San Andrés and Ryu [10] presents further rotordynamic measurements of a test rotor supported on flexure pivot tilting pad gas hydrostatic bearings for various mass imbalances, increasing supply pressures, and loadon-pad (LOP) and load-between-pad (LBP) configurations. In particular, rotor deceleration tests with a manual control of the supply pressure into the hybrid gas bearings are conducted to eliminate high amplitudes of rotor vibration while crossing the system critical speeds. Figure 2 depicts the amplitudes of rotor synchronous response for increasing supply pressures as reported in [10]. As the supply pressure increases, the stiffnesses of the gas bearings increase, thereby increasing the rotor-bearing system critical speed. The critical speed for 5 bar (absolute) feed pressure is $+10 \mathrm{krpm}$ higher 
than that for the no feed pressure condition. The measurements provide the opportunity for operating the rotor without traversing critical speeds by controlling the feed pressure into the bearings.

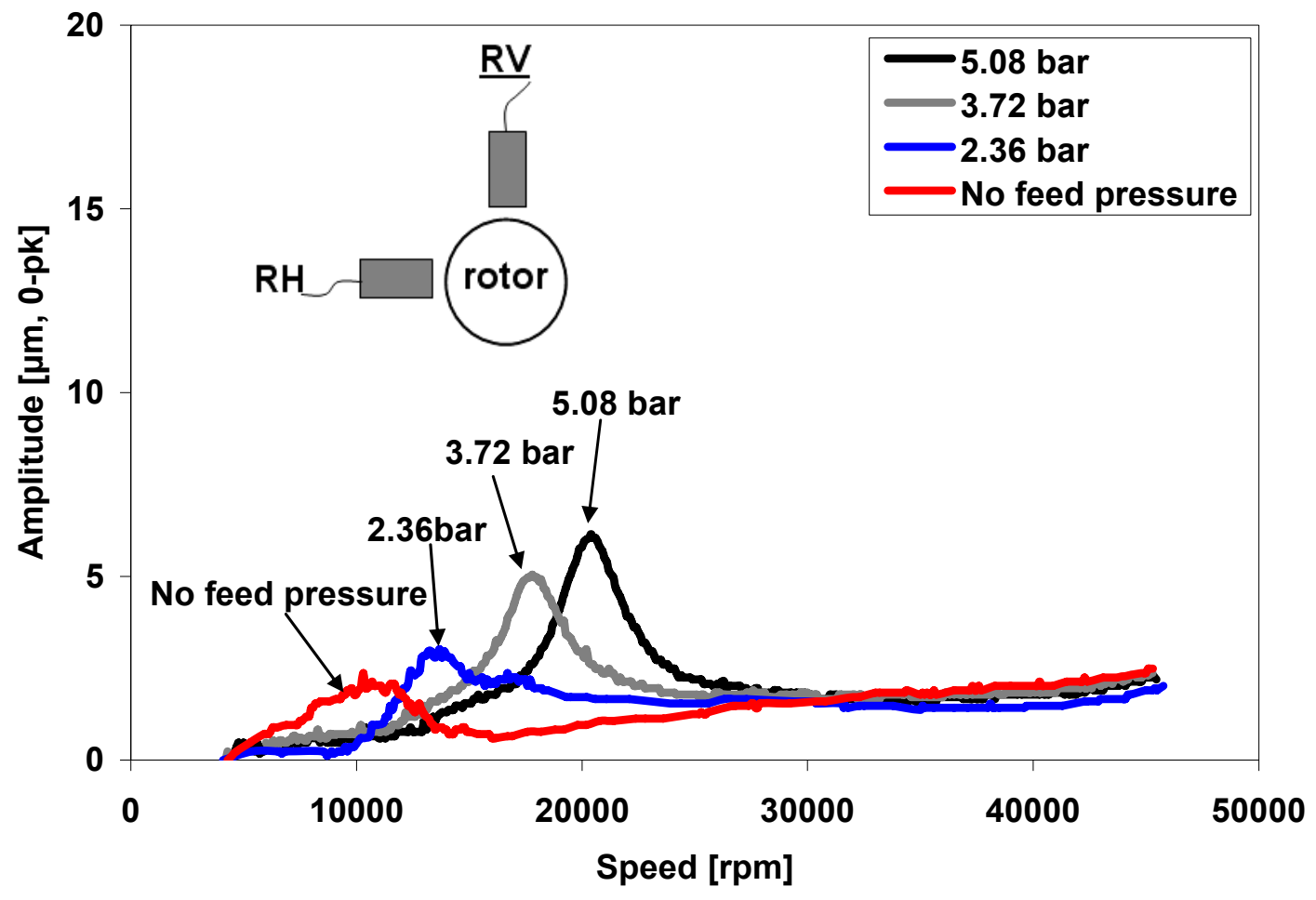

Fig. 2 Effect of increasing supply pressure on synchronous response of test rotor. Baseline imbalance. Right bearing vertical direction (RV). Taken from Ref. [10].

The main objective of this research is to advance the technology of hybrid gas bearings, for applications to oil-free high performance MTM, by demonstrating experimentally their rotordynamic performance, reliability and durability. To accomplish the desired objective, the current work focuses on suppressing excessive levels of rotor vibration which can occur while operating at the critical speeds of a rotor-bearing system. Vibration limits in a rotor-bearing system are essential to improve its reliability, performance, and life.

The present work advances prior research [10] and presents additional rotordynamic tests using control system of the supply pressure into the bearings to eliminate rotor motion peaks while passing through the critical speed of the rotor- 
bearing system. Open and closed loop control systems relate the supply pressure to the rotor speed and regulate the supply pressure into the test bearings. A simple and inexpensive electro-pneumatic air regulator controls the air supply pressure, whose magnitude is set inversely proportional to the rotor speed. Comprehensive rotor speed deceleration tests are performed to characterize the rotor response for various pressure supply control methods over certain rotor speed regions. The measured rotor responses for controlled supply air pressure are compared to predictions from computational models.

The current research paves a way to operate a hybrid gas bearing system with controlled external pressurization to avoid high amplitude rotor motions at system critical speeds. The results provide advances in gas bearing technology in terms of rotordynamic performance, reliability, and verification with predictions for the envisioned oil-free applications in high speed MTM, even when operating with worn bearing surfaces, i.e., enlarged and uneven clearances. 


\section{LITERATURE REVIEW}

High performance micro-turbomachinery (MTM) employs gas bearings because of their distinctive advantages over oil-lubricated bearings [1]. Gas bearings eliminate complex oil lubrication and sealing systems, and reduce friction, heat generation and power losses. Gas bearings, however, have low load-carrying capacity and small damping force coefficients because of the low gas viscosity, which typically is not large enough to effectively dissipate vibrational energy and to reduce amplitudes of rotor motion while traversing critical speeds of a rotor-bearing system [11].

In industrial practice, API specifications require tight vibration restrictions. API 610 [12] and API 617 [13] standards determine the vibration limit of a rotating shaft, i.e., $A_{u}<(5.2 \times 106 / N)^{0.5}$ and $A_{u}<25.4 \times(12000 / N)^{0.5}$ where $A_{u}$ is the peak-to-peak amplitude of unfiltered rotor vibration in $\mu \mathrm{m}$ and $N$ is the rotational speed in rpm, respectively. These standards also restrict the maximum $A_{u}$ to $50 \mu \mathrm{m}$ peak-to peak and $25 \mu \mathrm{m}$ peak-to peak, respectively. In petroleum, chemical and gas industries, API 610 and API 617 standards cover the requirements for centrifugal pumps and axial/centrifugal compressors, respectively.

San Andrés and Ryu [10] report imbalance responses of a high speed rotor supported on hybrid flexure pivot tilting pad gas bearings with worn clearances. The experimental results show that external pressurization into the test bearings stiffens the bearings, increasing the system (rigid rotor) critical speeds. Rotor deceleration demonstrations with manually controlled supply pressures eliminate the high amplitude rotor motions while the rotor passes through the system critical speeds region.

Nagaya et al [14] present an active vibration control method using memory-metal alloy supports to reduce rotor amplitude at the system critical speeds. The rigidity of the memory-metal alloy supports integrated with supporting ball bearings for the test rotor increases when heating control is applied, i.e., the stiffnesses of the bearing supports are controlled by heating and cooling of the memory-metal alloy materials. The memorymetal alloy supports are heated while approaching the system critical speeds to increase 
support stiffnesses, thereby raising the critical speeds. The rotor motion around the critical speed regime is not significantly reduced because of the response time lag of the memory-metal alloy supports. However, test results evidence that the stiffness control of bearing supports could be applicable to control the vibration at the critical speeds of a rotor-bearing system in TM.

Santos [15] proposes an active tilting pad bearing using hydraulic actuators to adjust the bearing force coefficients. An open-loop system with hydraulic actuators moves each of the four pads individually according to a predetermined position during operation of the test rotor-bearing system. The chamber pressure is changed via a proportional valve resulting in a displacement of the pads, which varies the film thickness. External pressurization into the test bearing increases its damping, thereby notably reducing the vibration amplitude of the rotor while crossing the system critical speeds.

To control the vibration amplitude of a rotor while passing through critical speeds in MTM, two approaches are available. One is the suppression of rotor vibration while crossing a critical speed by adding sufficient damping. The second is to increase the support bearing stiffnesses in order to raise the rotor-bearing system critical speed beyond its operating speed range. Passive and active controls of bearing force response characteristics in TM have successfully reduced vibration amplitudes at the system critical speed using the aforementioned methods.

Passive devices, i.e., absorber and dampers, enable transference or dissipation of the vibratory excitation energy, thus decreasing the vibration amplitude of a rotating shaft. In particular, passive devices do not require an external power source to operate. Squeeze film dampers (SFDs) and metal mesh dampers have been used to reduce the rotor sensitivity to imbalance. Zeidan et al. [16] report the distinct advantage of elastically supported SFDs, namely shifting of critical speeds in a rotor-bearing system. A significant overall bearing support stiffness reduction is achieved by introducing a SFD in series with the existing fluid film bearings. Note that the effect of vibration reduction with SFDs varies with rotor flexibility [17]. Zarzour and Vance [18] test a 
metal mesh damper, a short hollow cylinder made of woven metal material, as an alternative to SFDs in high temperature environments. Coast-down tests of a rotor in a power turbine test rig which integrates a metal mesh damper are performed for high operating temperatures. The metal mesh damper system provides $\sim 75 \%$ less rotor imbalance response amplitude at the first critical speed compared to a lubricated system with a SFD. The damping provided by the metal mesh is not significantly affected by operating temperature.

Actively controlled bearing systems offer advantages over passive devices such as versatility in adjusting to the load condition and machinery configuration, and at times not requiring of additional lubrication systems [19]. However, active vibration control systems typically require an external power source to operate actuators supplying controlled forces for ready delivery to the rotating structure [20]. Most force actuators are limited in load amplitude and frequency span; thus cannot easily compensate for imbalance-induced forces which can be large at high rotational speeds $[15,21]$.

Rho et al [22] investigate proportional, derivative and integral controls for control of active tilting pad bearings to reduce the imbalance response in a rotor-bearing system. A proportional control is more effective to suppress rotor imbalance response than a derivative control for speeds ranging from low to the critical speed of a rotorbearing system. On the other hand, a derivative control is more efficient than the proportional control for rotor speed operation beyond the critical speed region. An integral control for the bearings shows superior vibration amplitude reduction at very low speeds, but it increases the overall imbalance response over the entire speed range.

Qiu et al [23] present experimental results of vibration control in a turboexpander rotor supported on two actively controlled gas bearings, of three tilting pad type with embedded piezoelectric actuators. A feedback control system integrates PID controllers, actuators, and displacement sensors. The tests show that the subsynchronous vibration of a rotor-bearings system is remarkably suppressed with feedback control if the gains of the controllers are appropriately chosen. However, synchronous vibration amplitudes remain almost unchanged. 
Santos et al [24] describe rotordynamic measurements and analysis conducted on a rigid rotor supported on tilting pad bearings with active oil injection. The oil is injected into the test bearings, of four tilting pad type, which are connected to servo control systems. A servo control system consists of hydraulic servovalves, rotor displacement/velocity transducers, and PD feedback controllers. The servovalves are controlled by dynamic displacement and velocity of the rotor. A displacement feedback control reduces the rotor vibration amplitude at low frequencies. On the other hand, velocity feedback control lessens the amplitude of rotor motion at high frequencies. Combination of displacement and velocity signals with proper control gains provides the lowest rotor amplitude over extended rotor speed regions.

Bently et al [25] report the rotordynamic performance of a rotor supported on actively controlled hydrostatic oil-lubricated bearings in a turbocompressor. The four pocket bearings integrate high-speed electrohydraulic valves and a closed-loop feedback control system. The designed proportional controller concentrates on active anti-swirl of the fluid and pressurization control into the bearings. External pressurization increases the stiffnesses of the test bearings, thereby increasing the system critical speed beyond the operating speed range. The test bearings are also used as an input force device to determine modal stiffnesses in the rotor-bearing system.

Palazzolo et al [19] propose an active method, using linear quadratic optimization, to control the transient vibration of a rotor. An active system utilizing piezoelectric actuators, which consists of a stack of piezoelectric ceramic discs, controls the vibration of a flexible rotor. A computer directed grid search algorithm identifies the best feed back gains for the displacement type actuator. The experiments show that the optimal feedback gains are highly dependent on rotor speed. The active vibration control system, with the piezoelectric actuators at their optimum gains, reduces the rotor vibration significantly over the entire speed range.

The present research proposes a simple strategy, utilizing an inexpensive control device, to avoid high amplitudes of rotor motion within the critical speed range of a gas bearing system. The supply pressure into the hybrid gas bearings is manipulated to 
control the stiffnesses of the test bearings, thereby changing the system critical speed. The test results demonstrate the enhanced reliability and performance of hybrid gas bearings in oil-free MTM. 


\section{EXPERIMENTAL FACILITY}

\section{Test Rig}

Figure 3 depicts a layout of the gas bearing test rig and its instrumentation. The test rig has a steel casing integrating a brushless AC motor armature, maximum speed of $99 \mathrm{krpm}$. The motor controller offers $0.9 \mathrm{~kW}$ of continuous power. A K-type thermocouple monitors the temperature of the motor armature.

Three alignment bolts position the test bearings $120^{\circ}$ apart within their housings. Piezoelectric load cells installed between the bearing housing and each alignment bolt measure the dynamic forces transmitted to the rig casing. The airflow into the bearings is controlled by on/off valves and an adjustable air pressure regulator connected to the main shop line. Calibrated turbine flow meters measure the mass flow rate into each bearing with uncertainty of 0.05 Liter/min.

Two pairs of eddy current sensors, orthogonally positioned and facing the rotor ends, measure the rotor vibration amplitudes along the $X$-(vertical) and $Y$-(horizontal) planes. Rotor displacement voltage signals from the eddy current sensors are routed through a signal conditioner to bias their DC offset levels. The conditioned signals are input into LabVIEW ${ }^{\circledR}$ and ADRE® DAQ systems. Two analog oscilloscopes display the unfiltered real time rotor orbits for the left and right sides of the rotor. An infrared tachometer mounted at the right end of the rotor is a keyphasor signal for data acquisition. References [9,10,26,27] also detail the components of the test rig. 


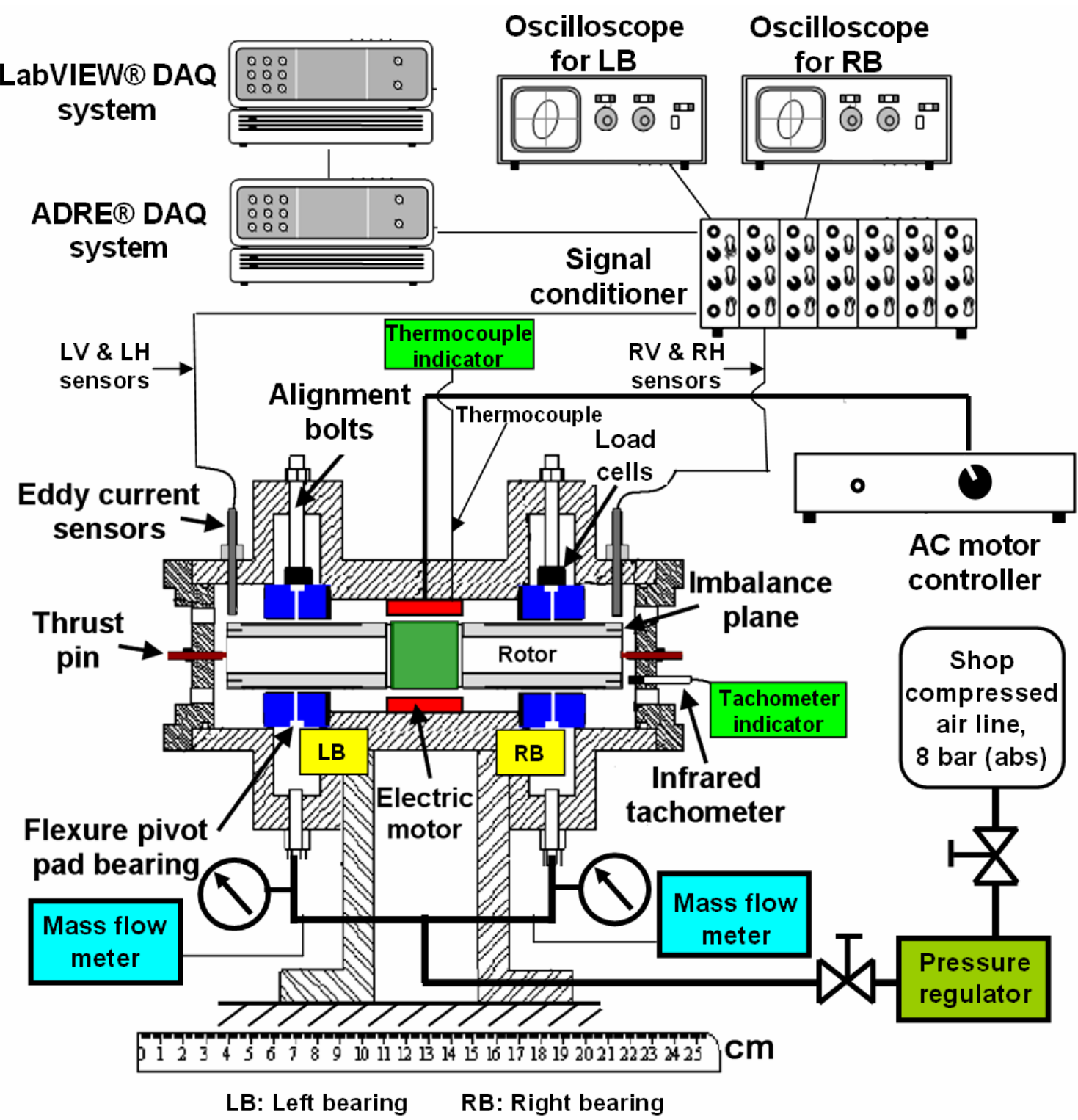

Fig. 3 Layout of gas bearing test rig and instrumentation.

\section{Test Rotor and Bearings}

Figure 4 depicts the test rotor consisting of a steel shaft, $15 \mathrm{~mm}$ in diameter and $190 \mathrm{~mm}$ in length and integrated brushless AC motor armature. Thrust pins with a spring hold the rotor axially. Two cylindrical steel sleeves are press-fit on the left and right sides of the shaft. The surface of the sleeves at the bearing locations is hard-chrome 
coated with a $0.25 \mathrm{~mm}$ thickness. The right journal sleeve has a smaller diameter than the left journal sleeve due to extensive wear during prior rotor coast down tests [10]. Eight holes, $1 \mathrm{~mm}$ in diameter and $12 \mathrm{~mm}$ in a radial distance from the rotor center, are equally spaced on each rotor end face. Balancing and added masses are inserted in these holes.

Figure 5 shows a technical drawing of the test flexure pivot gas bearings. The bearings, made of bronze, have four pads with $60 \%$ pad offset. Prior extensive testing with the bearings $[9,10]$ left the pads' surfaces with uneven wear. The present condition of the bearings shows quite dissimilar clearances along the circumference and axial lengths of each pad. The original bearing nominal clearance and dimensionless pad preload, as reported in [9], are $40 \pm 4.5 \mu \mathrm{m}$ and $40 \%$, respectively. Presently, the estimated radial clearances vary from $40 \sim 80 \mu \mathrm{m}$ for the left bearing and $30 \sim 60 \mu \mathrm{m}$ for the right bearing. The left bearing has a much larger clearance variation than the right bearing. Figure 6 depicts currently measured bearing radial clearances on the test bearings, and a comparison with prior measurements reported in [10]. Table 1 lists the main parameters of the test rotor and the bearings. 


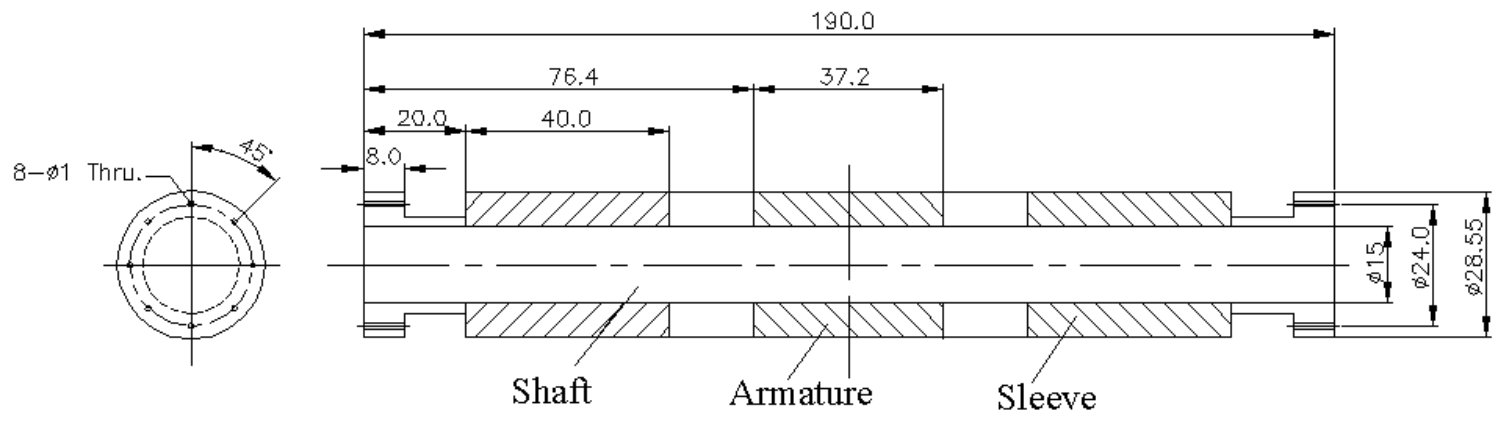

Fig. 4 Schematic view of rotor (units: $\mathrm{mm}$ ).

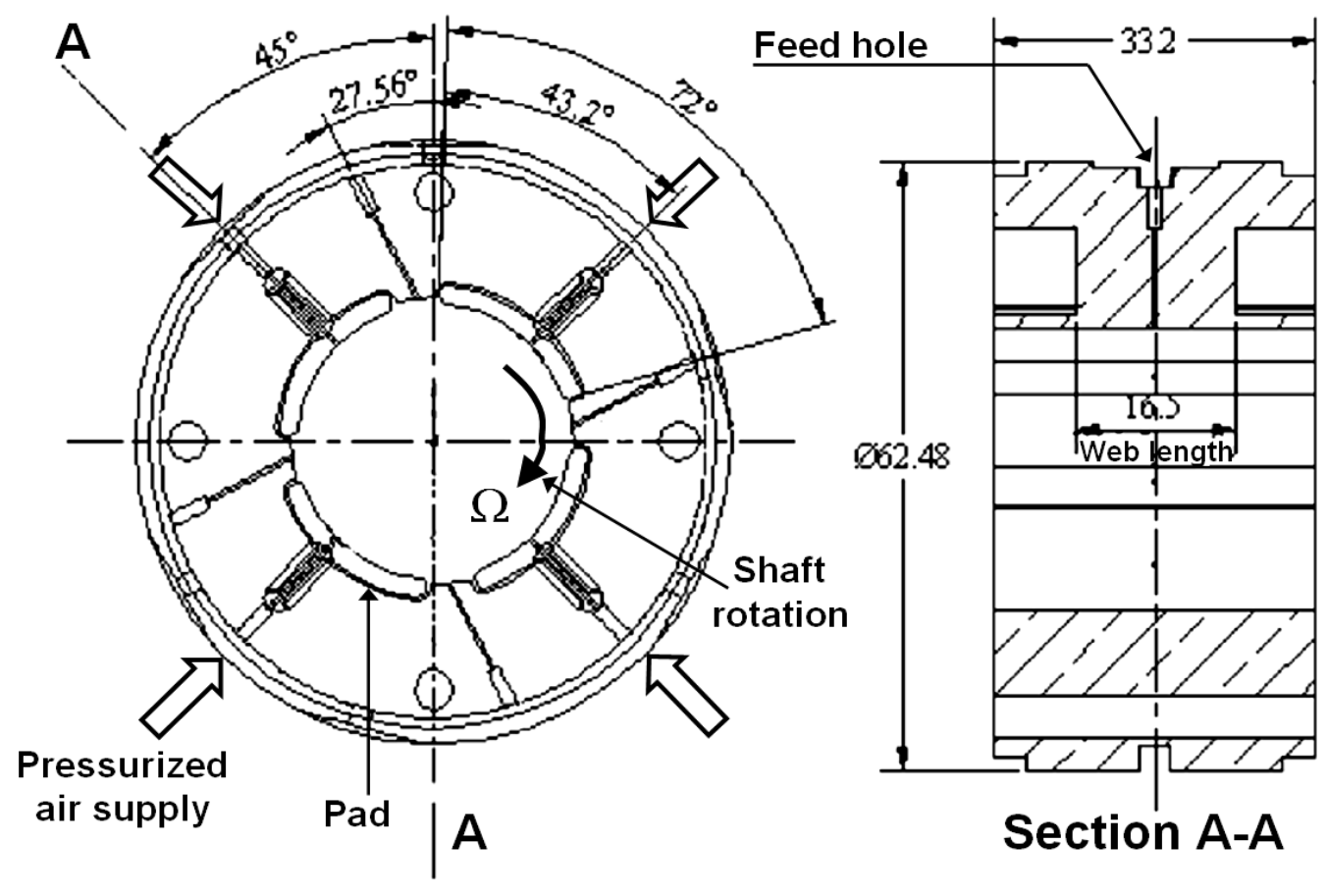

Fig. 5 Drawing of test flexure pivot gas bearing (unit: $\mathrm{mm}$ ). 


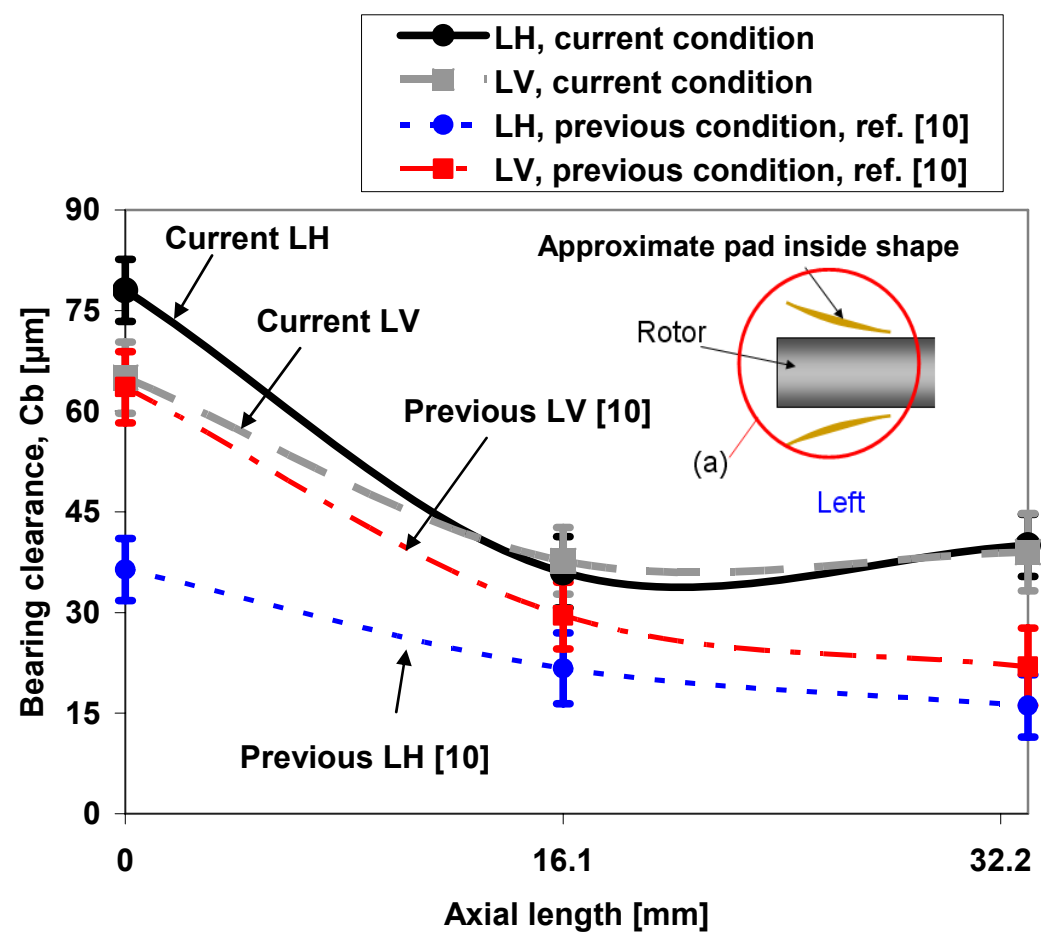

(a) Left bearing

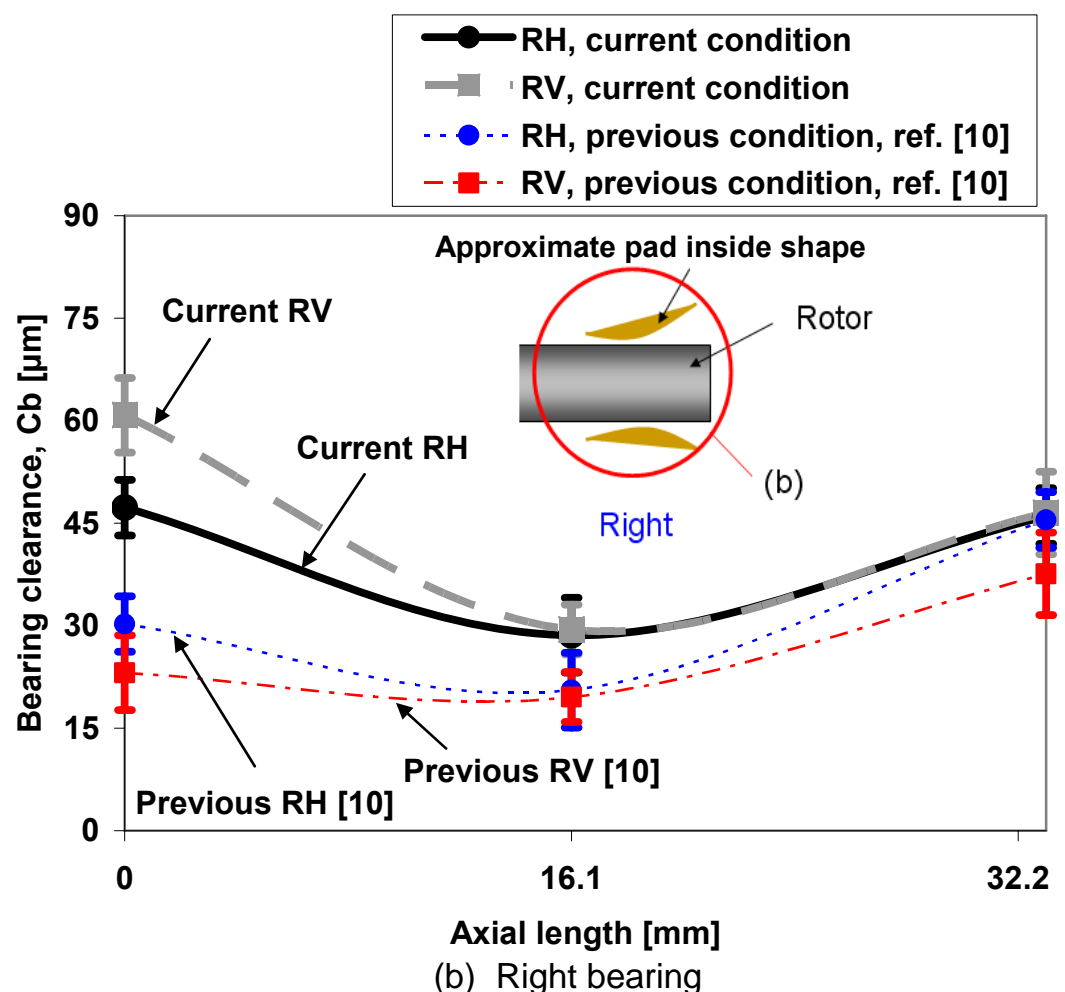

Fig. 6 Estimated bearing radial clearances of left $(L)$ and right $(R)$ test bearings along horizontal $(\mathrm{H})$ and vertical $(\mathrm{V})$ directions. Inserts show approximate axial shape of pads. 
Table 1. Main parameters of test rotor and bearings

\begin{tabular}{|c|c|c|c|}
\hline \multicolumn{2}{|c|}{ Parameter } & Magnitude & Unit \\
\hline \multicolumn{2}{|c|}{ Rotor mass, $M$} & $0.825 \pm 0.005$ & $\mathrm{~kg}$ \\
\hline \multirow{2}{*}{$\begin{array}{c}\text { Rotor diameter, } \\
D_{j}\end{array}$} & Left side & $28.555 \pm 0.001$ & $\mathrm{~mm}$ \\
\hline & Right side & $28.551 \pm 0.001$ & $\mathrm{~mm}$ \\
\hline \multicolumn{2}{|c|}{ Bearing axial length, $L$} & 33.2 & $\mathrm{~mm}$ \\
\hline \multicolumn{2}{|c|}{ Pads number and arc length } & $4\left(72^{\circ}\right)$ & \\
\hline \multicolumn{2}{|c|}{ Pad pivot offset } & $60 \%$ & \\
\hline \multicolumn{2}{|c|}{ Pad mass moment of inertia, $I_{p}$} & 0.253 & $\mathrm{~g}-\mathrm{mm}^{2}$ \\
\hline \multicolumn{2}{|c|}{ Web rotational stiffness, $K_{\delta \delta}$} & 20 & $\mathrm{Nm} / \mathrm{rad}$ \\
\hline \multicolumn{2}{|c|}{ Number of feed orifices } & 4 & \\
\hline \multicolumn{2}{|c|}{ Feed orifice diameter, $d_{o}$} & 0.62 & $\mathrm{~mm}$ \\
\hline \multirow{2}{*}{$\begin{array}{c}\text { Bearing } \\
\text { diameter, } \\
D_{b}\end{array}$} & Left side & $28.63 \sim 28.71$ & $\mathrm{~mm}$ \\
\hline & Right side & $28.61 \sim 28.67$ & $\mathrm{~mm}$ \\
\hline \multirow{2}{*}{$\begin{array}{c}\text { Bearing } \\
\text { clearance, } C_{b}\end{array}$} & Left side & $40 \sim 80$ & $\mu \mathrm{m}$ \\
\hline & Right side & $30 \sim 60$ & $\mu \mathrm{m}$ \\
\hline
\end{tabular}

Pressurized air flows through the orifices into the middle plane of each pad. The actual orifice diameter is estimated at $0.62 \mathrm{~mm}$, which is slightly larger than the design value of $0.58 \mathrm{~mm}$. The orifice diameter is estimated by inserting thin steel guitar strings of different diameters through the orifice. The bearings are installed in the load-on-pad (LOP) configuration. Note that reference [10] compares the rotordynamic responses of the test rotor-bearing system under load-on-pad (LOP) and load-between-pad (LBP) configurations. The designed flexure web rotational stiffness of the test bearings is 20 $\mathrm{Nm} / \mathrm{rad}$.

\section{Electronic Air Regulator and Tachometer for Supply Pressure Control System}

The electro-pneumatic air regulator controls the air supply pressure in proportion to the rotational speed of the test rotor (See Appendix B). The tachometer integrates a 
digital to analog converter which provides a voltage output according to a customized rotor speed range. The analog output from the tachometer is an input to the electronic air regulator. The analog output changes in step wise form, 4096 steps, throughout the specified voltage range. The step size is $\sim 0.0244 \%$ (1/4096 step) of the total controlled speed range. Note that the tachometer acquires data and updates the analog output at 25 times per second, i.e., every 40 milliseconds. The sensitivity (voltage/rpm) of the tachometer output depends on the user-defined speed range for control. A narrow speed range leads to an abrupt increase of the voltage output as the speed changes.

The air regulator offers a proportional pressure in compliance with an input signal, i.e., rotor speed. As the rotor speed decelerates, the supply pressure increases steadily from a low pressure to a high pressure. Note that the controller has approximately $0.3 \sim 0.4$ second of time delay. A detailed description on the control loop follows later. 


\section{EXPERIMENTAL PROCEDURE}

Figures 7 and 8 depict schematic views of open and closed loop control systems for supply air into the test bearings, respectively. Table 2 lists the eight test operating conditions based on various pressure supply control methods and preset rotor speed regions.

Operating conditions \#1 \#4 represent an open control loop, with manual setup of supply pressure using an adjustable pressure regulator. Pressure gauges monitor the supply pressure into each test bearing. Note that operating condition \#1 is a coast-down rotor speed demonstration without any pressure control, i.e., with a constant supply pressure over the whole coast-down speed range.

Closed loop control of the supply pressure governed by rotor speed, using the electro-pneumatic air regulator, is established for operating conditions \#5 \#8. The electro-pneumatic air regulator automatically adjusts the supply pressure as per the control desired. This device consists of controller, control valve, and pressure sensor as shown in Figure 8. When the voltage of the input signal raises, the controller valve opens, thereby supply pressure passes through it. This pressure feeds back to the controller via a pressure sensor. The controller compares the supply pressure with the customized reference value based on the rotor speed range, and determines the final output pressure. The manipulated pressure, the output of the controller, is the supply pressure into the test bearings.

For coast-down rotor speed tests (operating conditions \#1, \#5, and \#6), the power to the motor controller is turned off allowing the rotor to freely coast down from 40 krpm. For operator set speed demonstrations (operating conditions \#2, \#3, \#4, \#7, and \#8), the rotor speed is set manually, starting at $40 \mathrm{krpm}$ and ending at $11.5 \mathrm{krpm}$; and then, the motor power is turned off. Note that the operator set speed demonstration obviously provides a longer deceleration time over the controlled feed pressure versus rotor speed region. 
For operating conditions \#2 and \#3, the rotor speed is decreased manually, i.e., starting at $40 \mathrm{krpm}$. When reaching $\sim 14.2 \mathrm{krpm}$, the supply pressure is manually increased from 2.36 bar to 5.08 bar (absolute) using an adjustable pressure control valve, as shown in Figure 9 (a). Figure 10 display the air pressure supply variation for operating conditions \#2 and \#3. Operating condition \#2 provides an instantaneous onestep pressure increase of 2.72 bar from 2.36 bar to 5.08 bar (absolute). Operating condition \#3 implements a four-step supply pressure increase, 0.68 bar each step from 2.36 bar to 5.08 bar (absolute) with a 10 second time lag. For operating condition \#4, the supply pressure varies as in operating condition \#3, increasing from 2.36 bar to 5.08 bar (absolute) over a narrow speed range $(13.9 \sim 13.0 \mathrm{krpm})$ as depicted in Figure 9 (b).

Operating conditions \#5 \#8 utilize the electro-pneumatic air regulator for active control of the supply pressure. Figure 9 (c) depicts the supply pressure versus rotor speed for operating conditions \#6 and \#8. The supply pressure increases continuously from 2.36 bar to 5.08 bar (absolute) over the speed range $14.2 \sim 13.0 \mathrm{krpm}$.

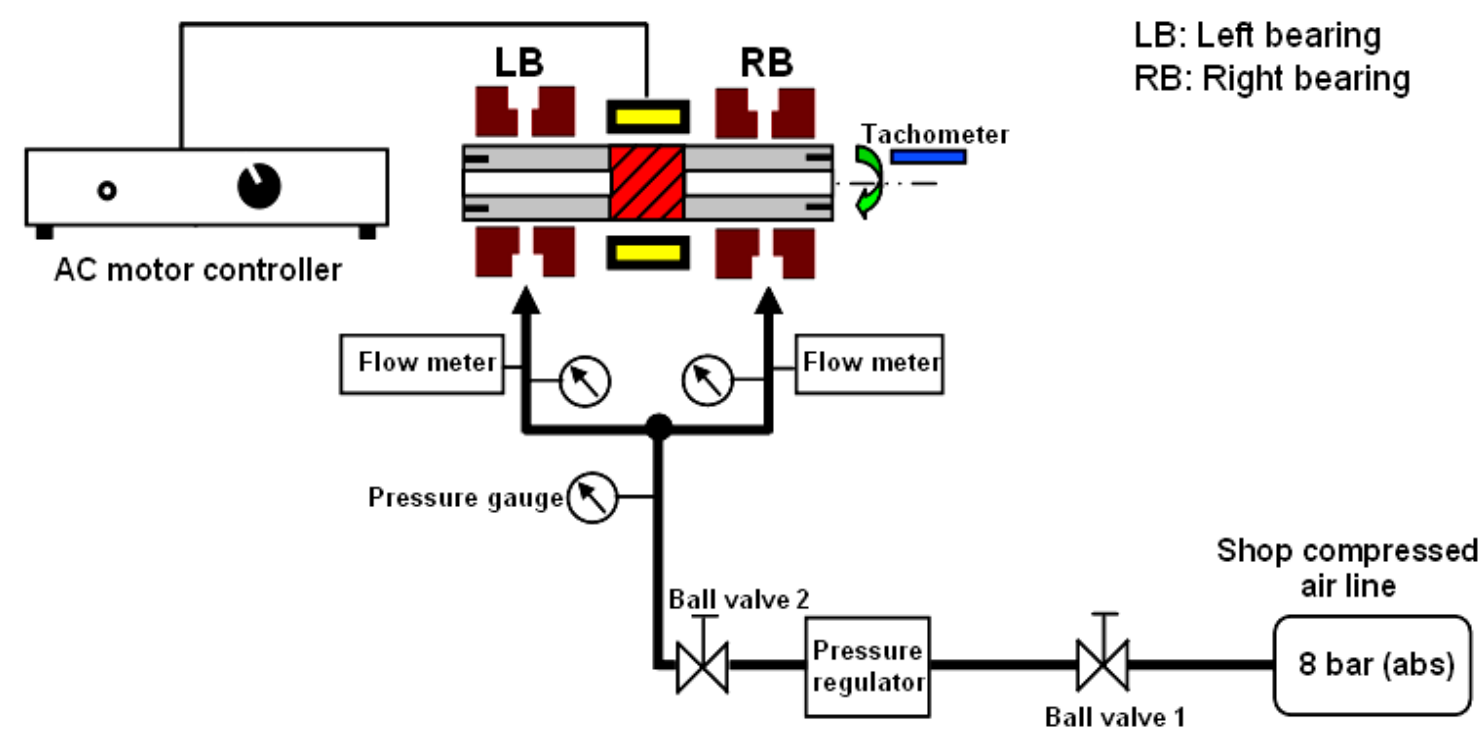

Fig. 7 Schematic view of air supply system with manual operation of adjustable pressure regulator. Open loop control. Operating conditions \#1 \#4. 


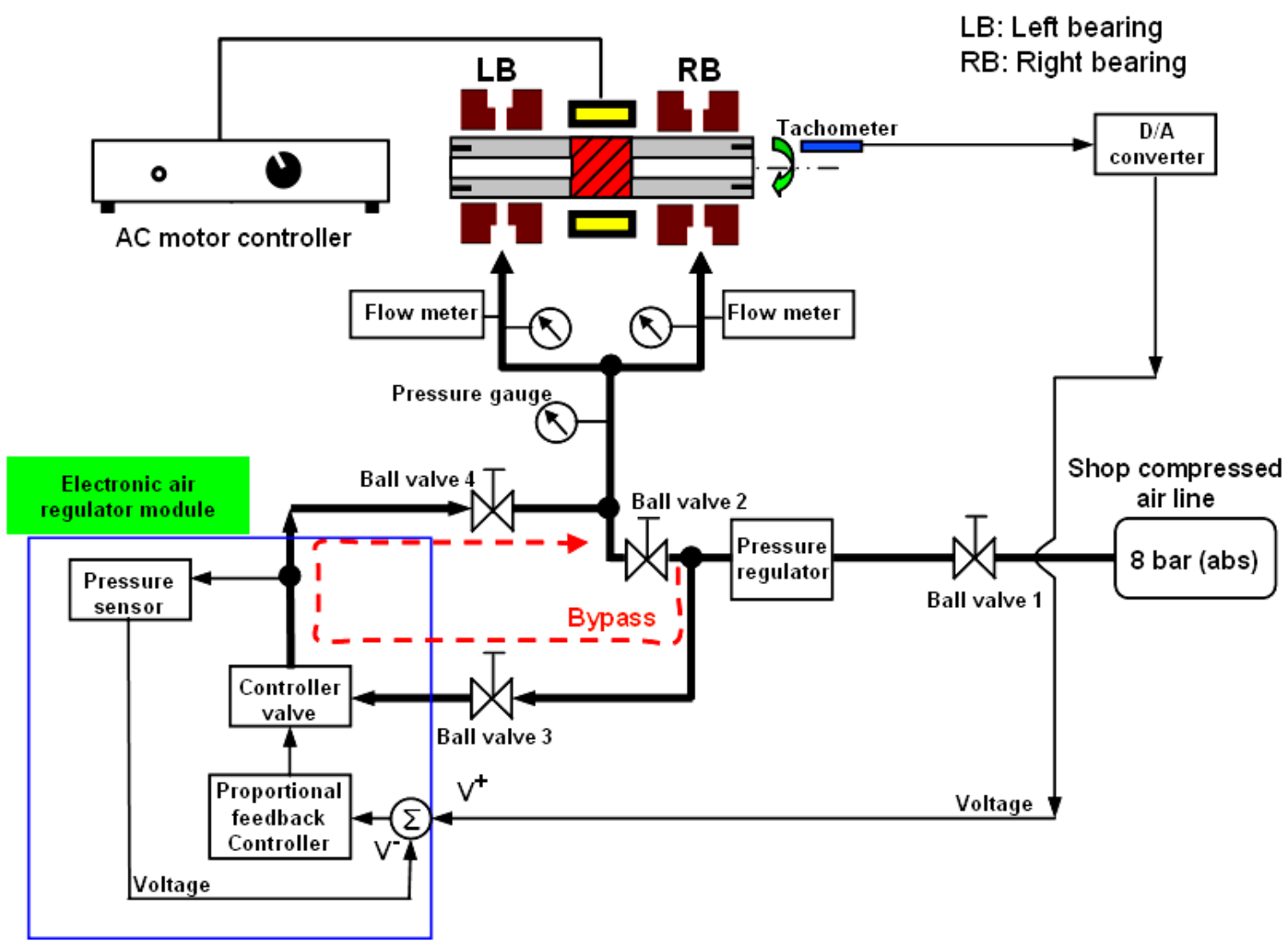

Fig. 8 Schematic view of automated air supply system with electronic air regulator. Closed loop control. Operating conditions \#5 \#8. 
Table 2 Summary of rotor speed and feed pressure conditions

\begin{tabular}{|c|c|c|c|c|}
\hline \multirow[b]{2}{*}{$\begin{array}{l}\text { Operating } \\
\text { condition \# }\end{array}$} & \multicolumn{4}{|c|}{ Control strategy } \\
\hline & $\begin{array}{l}\text { Speed control } \\
\text { method }\end{array}$ & $\begin{array}{l}\text { Preset rotor } \\
\text { speed region } \\
\text { for } \\
\text { pressure } \\
\text { control }\end{array}$ & $\begin{array}{l}\text { Method of } \\
\text { controlling } \\
\text { supply } \\
\text { pressure }\end{array}$ & $\begin{array}{c}\text { Step \# of supply } \\
\text { pressure control } \\
\text { over } \\
\text { preset speed region }\end{array}$ \\
\hline 1 & Coast down & None & None & - \\
\hline 2 & $\begin{array}{l}\text { Operator set } \\
\text { speed }\end{array}$ & $14.2 \mathrm{krpm}$ & Manual & $\begin{array}{c}1 \text { step, } \\
\text { Fig.9(a) \& Fig.10(a) }\end{array}$ \\
\hline 3 & $\begin{array}{l}\text { Operator set } \\
\text { speed }\end{array}$ & $14.2 \mathrm{krpm}$ & Manual & $\begin{array}{l}4 \text { steps, } \\
\text { Fig. 9(a) \& } \\
\text { Fig.10(b) }\end{array}$ \\
\hline 4 & $\begin{array}{l}\text { Operator set } \\
\text { speed }\end{array}$ & $\begin{array}{c}13.9 \sim 13.0 \\
\mathrm{krpm}\end{array}$ & Manual & 4 steps, Fig.9(b) \\
\hline 5 & Coast down & $14.2 \mathrm{krpm}$ & Controlled & 1 step, Fig.9(a) \\
\hline 6 & Coast down & $\begin{array}{c}14.2 \sim 13.0 \\
\mathrm{krpm}\end{array}$ & Controlled & $\begin{array}{l}\text { Continuous, } \\
\text { Fig.9(c) }\end{array}$ \\
\hline 7 & $\begin{array}{l}\text { Operator set } \\
\text { speed }\end{array}$ & $14.2 \mathrm{krpm}$ & Controlled & 1 step, Fig.9(a) \\
\hline 8 & $\begin{array}{l}\text { Operator set } \\
\text { speed }\end{array}$ & $\begin{array}{l}14.2 \sim 13.0 \\
\text { krpm }\end{array}$ & Controlled & $\begin{array}{l}\text { Continuous, } \\
\text { Fig.9(c) }\end{array}$ \\
\hline
\end{tabular}




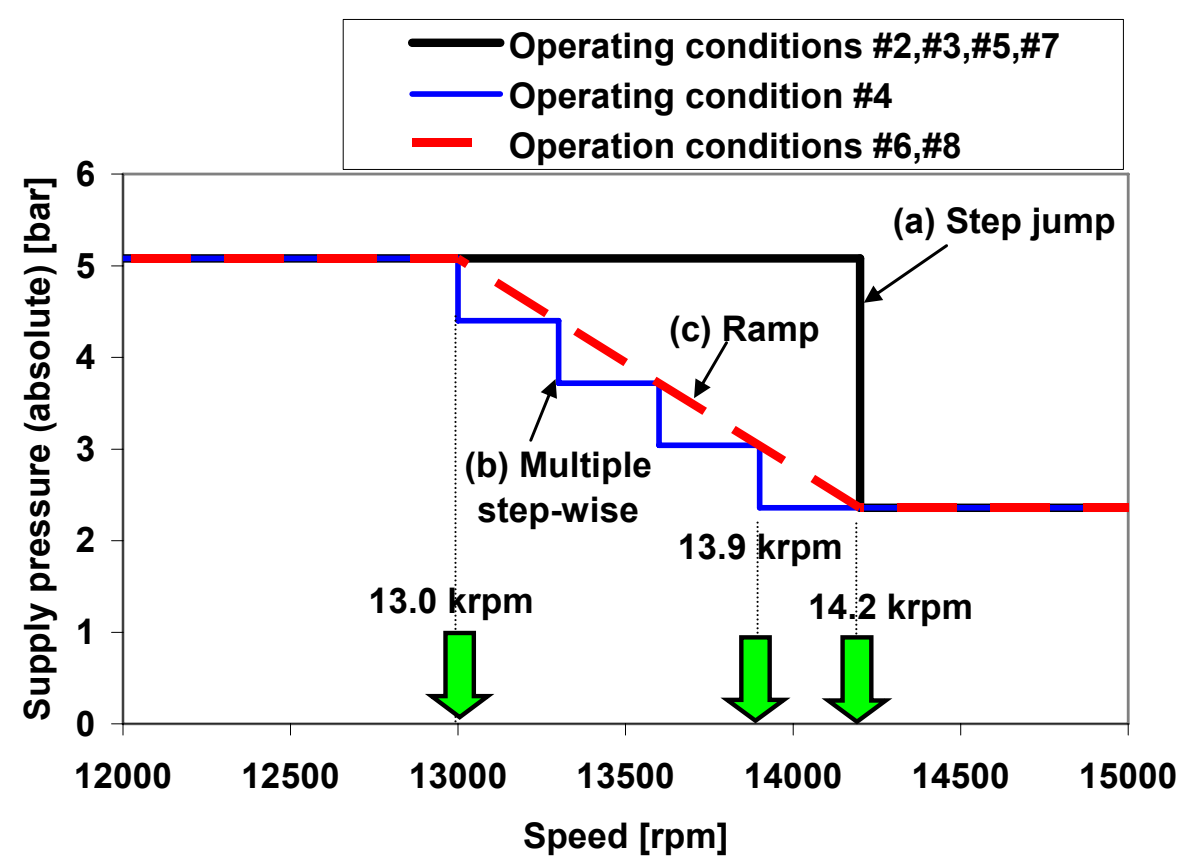

Fig. 9 Controlled supply pressure versus rotor speed for operating conditions \#2 \#8.

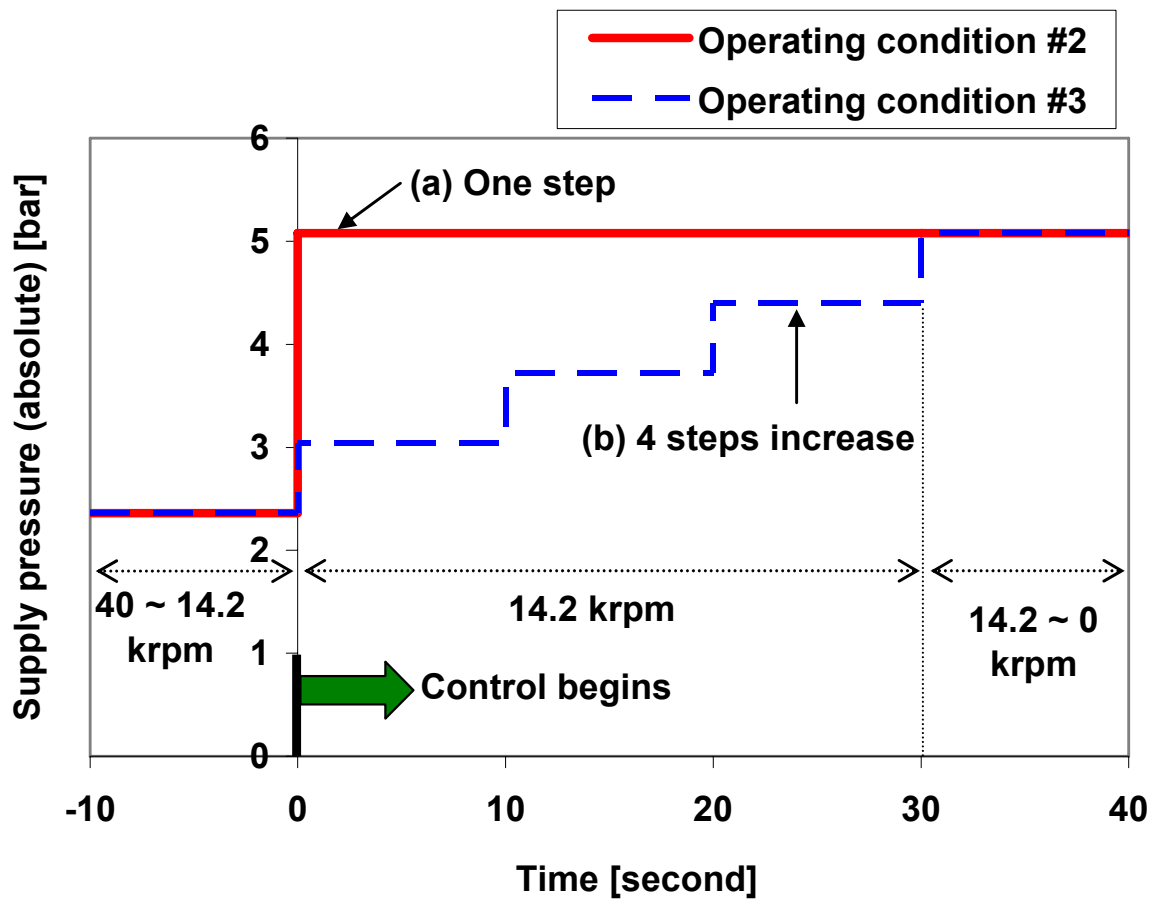

Fig. 10 Increase of controlled supply pressure over a selected time span. Operating conditions \#2 and \#3. 


\section{EXPERIMENTAL RESULTS}

\section{Determination of Control Speed Regime for Air Regulator}

In reference [10], rotor deceleration tests with manual changes in supply pressure are performed to reduce rotor motion amplitudes while passing through a critical speed. Current demonstrations include controlled changes of supply pressure using the electropneumatic air regulator, and also manual changes in external pressurization.

Figure 11 depicts the amplitudes of rotor synchronous motions along the right horizontal direction $(\mathrm{RH})$ for operating condition \#1 at supply pressures from 2.36 bar to 5.08 bar (absolute). Figure 12 shows the identified system critical speeds versus supply pressure from shaft motion measurements near the right bearing, horizontal direction $(\mathrm{RH})$. External pressurization into the gas bearings increases their direct stiffnesses, thereby rising the system critical speeds. The critical speed increases linearly with supply pressure.

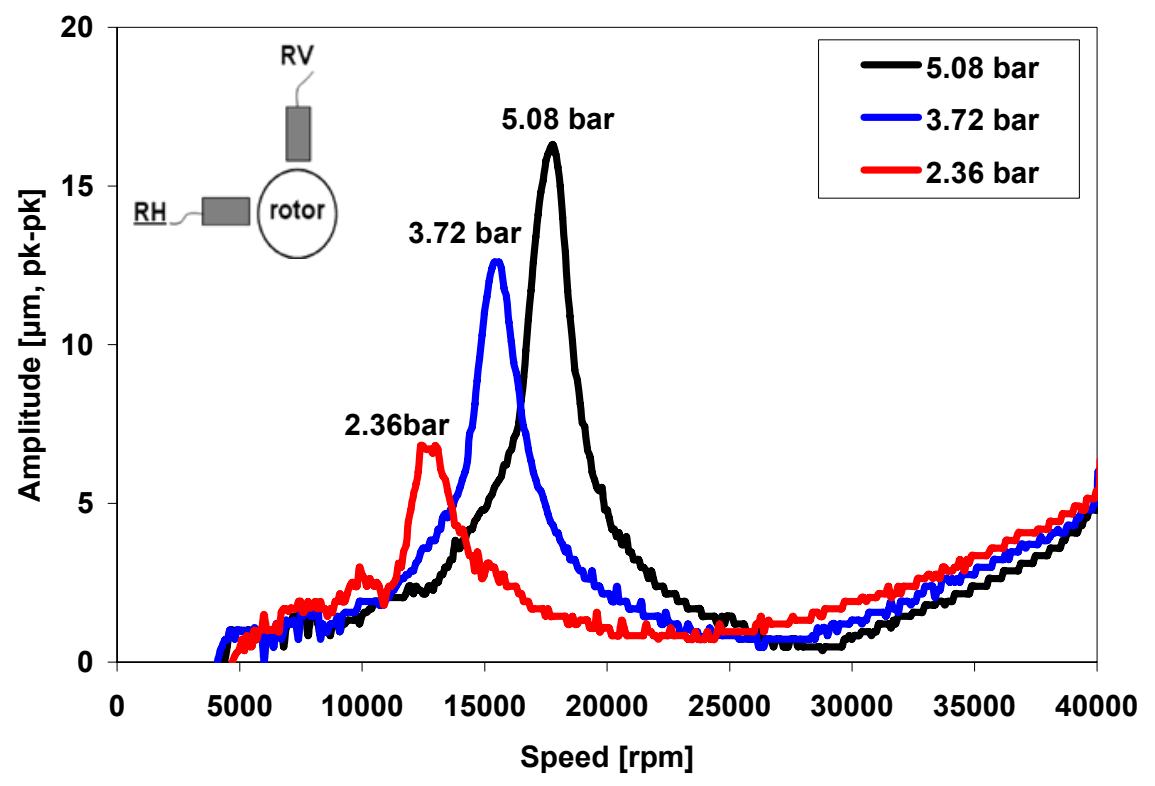

Fig. 11 Synchronous rotor amplitudes versus rotor speed for three supply pressures. Right bearing horizontal direction (RH). Operating condition \#1 (constant pressure supply, rotor speed coast down). 


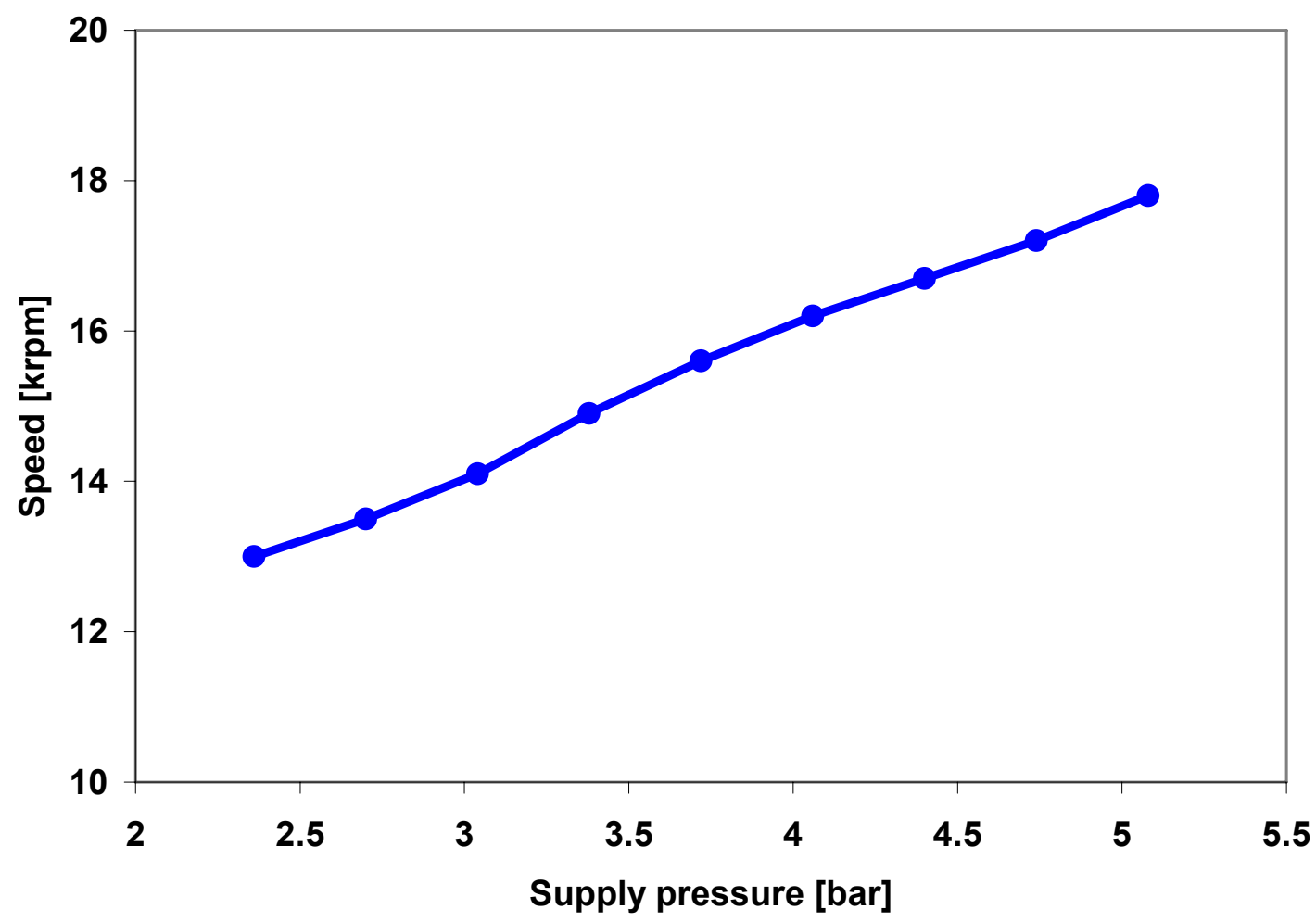

Fig. 12 Critical speed of test rotor-bearing system versus supply pressure into bearings. Right bearing horizontal direction (RH). Operating condition \#1 (constant pressure supply, rotor speed coast down).

Figure 13 depicts the rotor speed region for supply pressure control. The supply pressure into the test bearings will be manipulated within the rotor speed range between $14.2 \mathrm{krpm}$ (an intersection of the rotor synchronous motions for 2.36 bar and $5.08 \mathrm{bar}$ ) and $13.0 \mathrm{krpm}$ (the critical speed for $2.36 \mathrm{bar}$ ).

While coasting down from the top speed of $40 \mathrm{krpm}$ to $14.2 \mathrm{krpm}$, the supply pressure is maintained at the lowest pressure of 2.36 bar (absolute). The supply pressure will be increased from 2.36 bar to 5.08 bar (absolute) while the rotor traverses the speed region between 14.2 and $13.0 \mathrm{krpm}$, as shown later. 


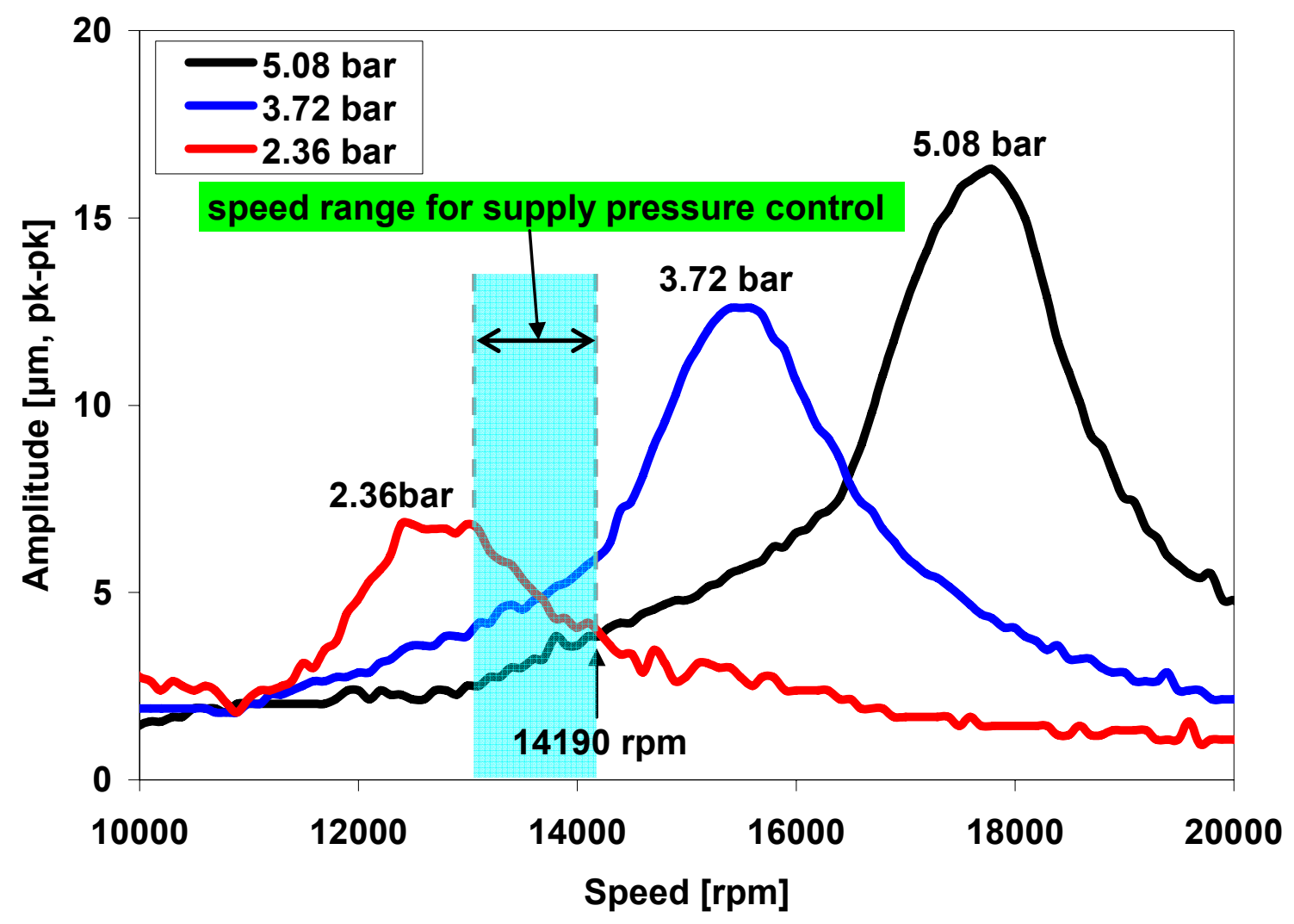

Fig. 13 Determination of $P_{s}$ control speed range. Right bearing horizontal direction (RH). Operating condition \#1 (constant pressure supply, rotor speed coast down).

\section{Estimation of Air Pressure Regulator Response Delay for Test System}

Figure 14 depicts the recorded coast-down speed of the test rotor versus time for bearings supplied with a 2.36 bar absolute feed pressure. Note that the controller in the air pressure regulator has a response time lag of approximately $0.3 \sim 0.4$ second (manufacturer provided). Over the speed range from 15 to $14 \mathrm{krpm}$, the deceleration rate of the shaft is approximately $210 \mathrm{rpm} / \mathrm{s}$. Therefore, the time lag of the air regulator will cause a response delay of approximately $60 \sim 85 \mathrm{rpm}$. Thus, the regular has an increasing supply pressure rate equal to $[(5.08 \mathrm{bar}-2.36 \mathrm{bar}) /(60 \sim 85 \mathrm{rpm})] \times(210$ $\mathrm{rpm} / \mathrm{s})=9.45 \sim 6.72 \mathrm{bar} / \mathrm{s}$. Recall that the air pressure regulator is operated according to the output voltages of the tachometer which is proportional to the rotor speed. 


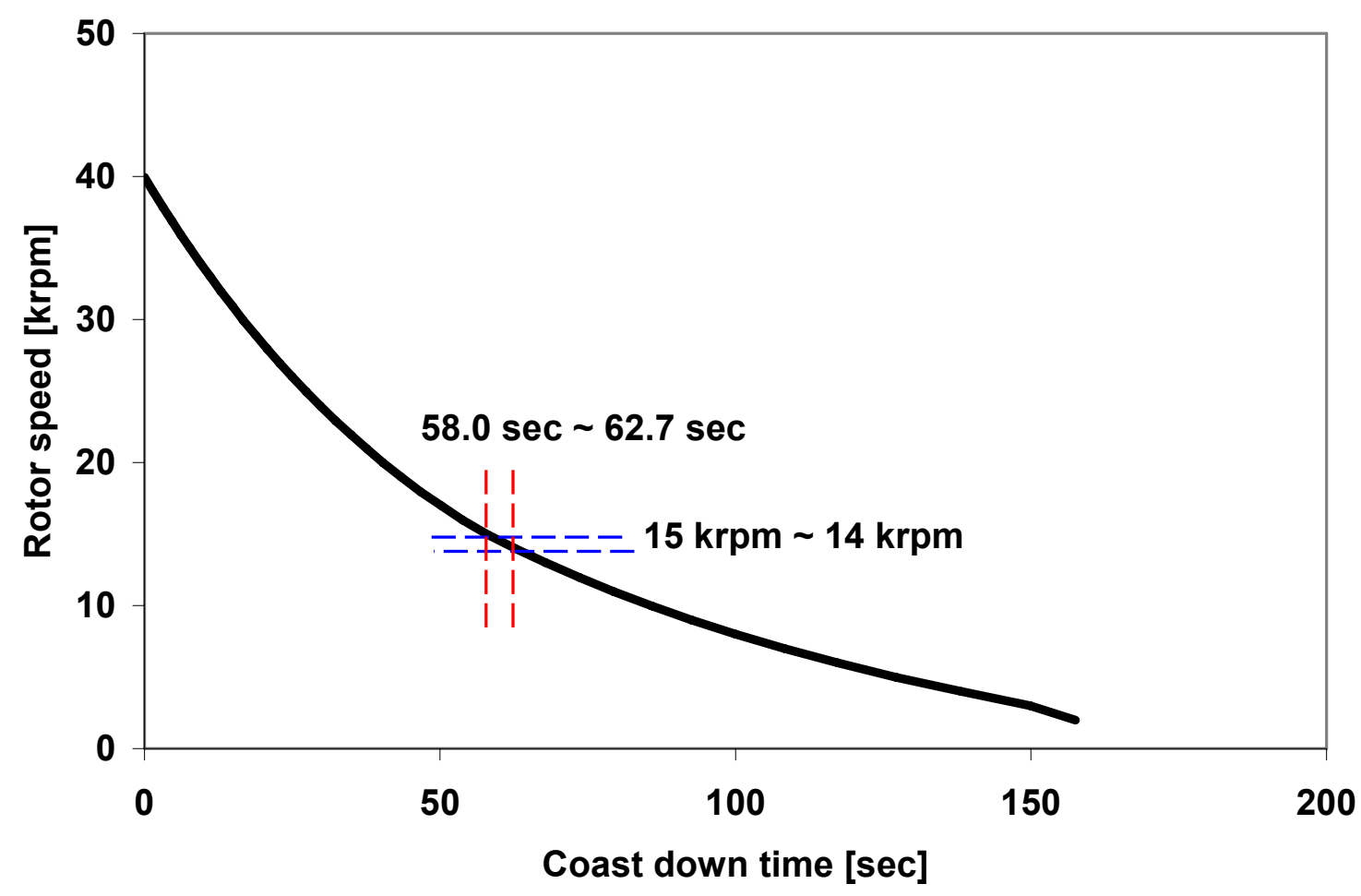

Fig. 14 Estimation of shaft speed change rate based on recorded coast down rotor speed versus time. 2.36 bar feed pressure. Operating condition \#1 (constant pressure supply, rotor speed coast down).

\section{Measured Rotor Response Amplitudes for Each Operating Configuration}

Figures 15 through 18 depict the amplitudes of rotor synchronous motion for each operating configuration. The graphical inserts in the figures recall the supply air feeding methods for each operating configuration. In all figures, tests results with a fixed supply pressure maintained throughout the whole rotor speed range are shown.

Figure 15 shows that the peak amplitude of rotor response is completely eliminated by the sudden increase in supply pressure for both operating conditions \#2 and \#3.

For operating condition \#4, the supply pressure into the test bearings is increased in a similar fashion as in prior measurements reported in Ref. [10]. The rotor motion amplitude abruptly decreases while varying the supply pressure over a narrow speed region from $13.9 \mathrm{krpm}$ to $13.0 \mathrm{krpm}$, as shown in Figure 16. Deceleration fixed rotor speed tests demonstrate that manual step-control of the supply pressure can effectively 
reduce the rotor synchronous response amplitudes while crossing the system critical speed.

Based on the test results shown in Figure 15, the electro-pneumatic air regulator is used with a closed loop to control the supply pressure. Figure 17 shows that the rotor responses for operating configurations $\# 5$ and $\# 7$ have a similar behavior over the entire rotor speed range.

Figure 18 shows the rotor synchronous responses for a continuous (ramp) increase in supply pressure to the bearings. Over the narrowly selected speed region, the rotor response evidences a distinct peak over the controlled pressure regime. The rotorbearing system experiences a sudden critical speed when the pressure supply is increased continuously from 2.36 bar to 5.08 bar within $14.2 \sim 13.0 \mathrm{krpm}$.

Both the fixed speed rotor deceleration and speed coast-down operation render similar rotor synchronous motions for each method of supplying the feed pressure. A step change in supply pressure is more effective than a ramp increase for reducing high vibration amplitudes of the rotor while crossing the system critical speeds. 


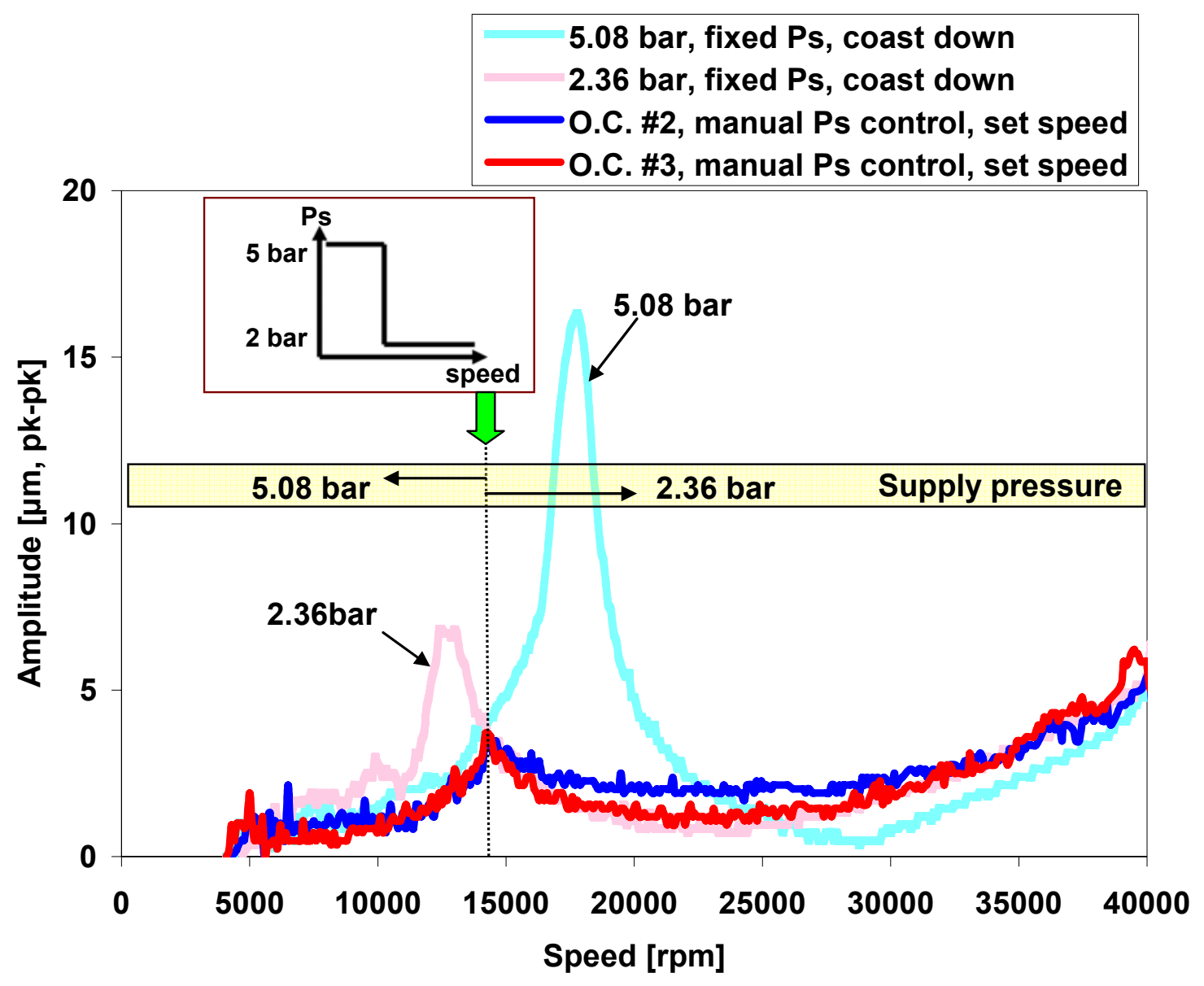

Fig. 15 Rotor synchronous response versus shaft speed. Right bearing horizontal direction (RH). Operating conditions (O.C.) \#2 and 3. Manual pressure supply setting. 


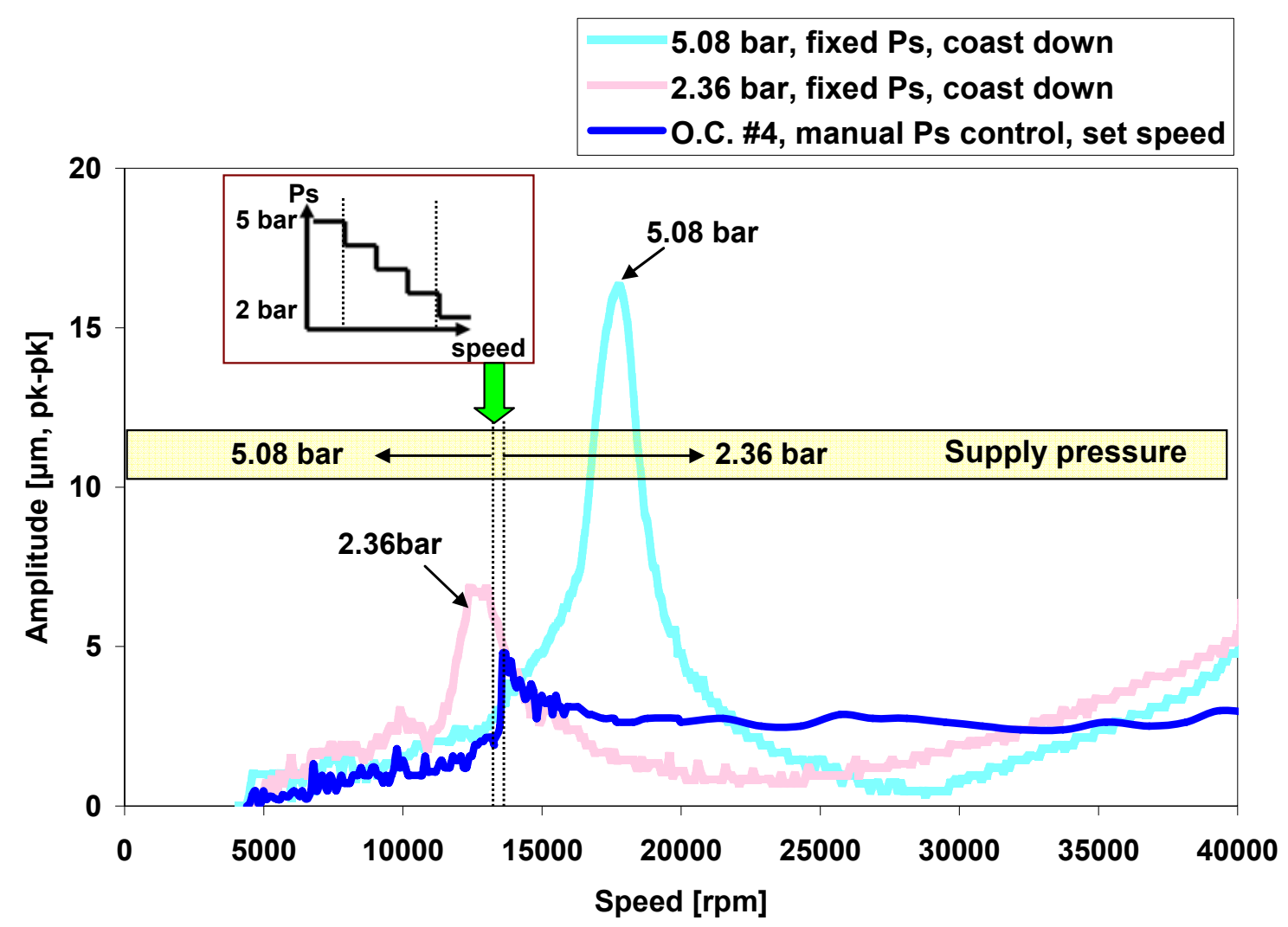

Fig. 16 Rotor synchronous response versus shaft speed. Right bearing horizontal direction (RH). Operating condition (O.C.) \#4. Step-wise manual pressure supply setting. 


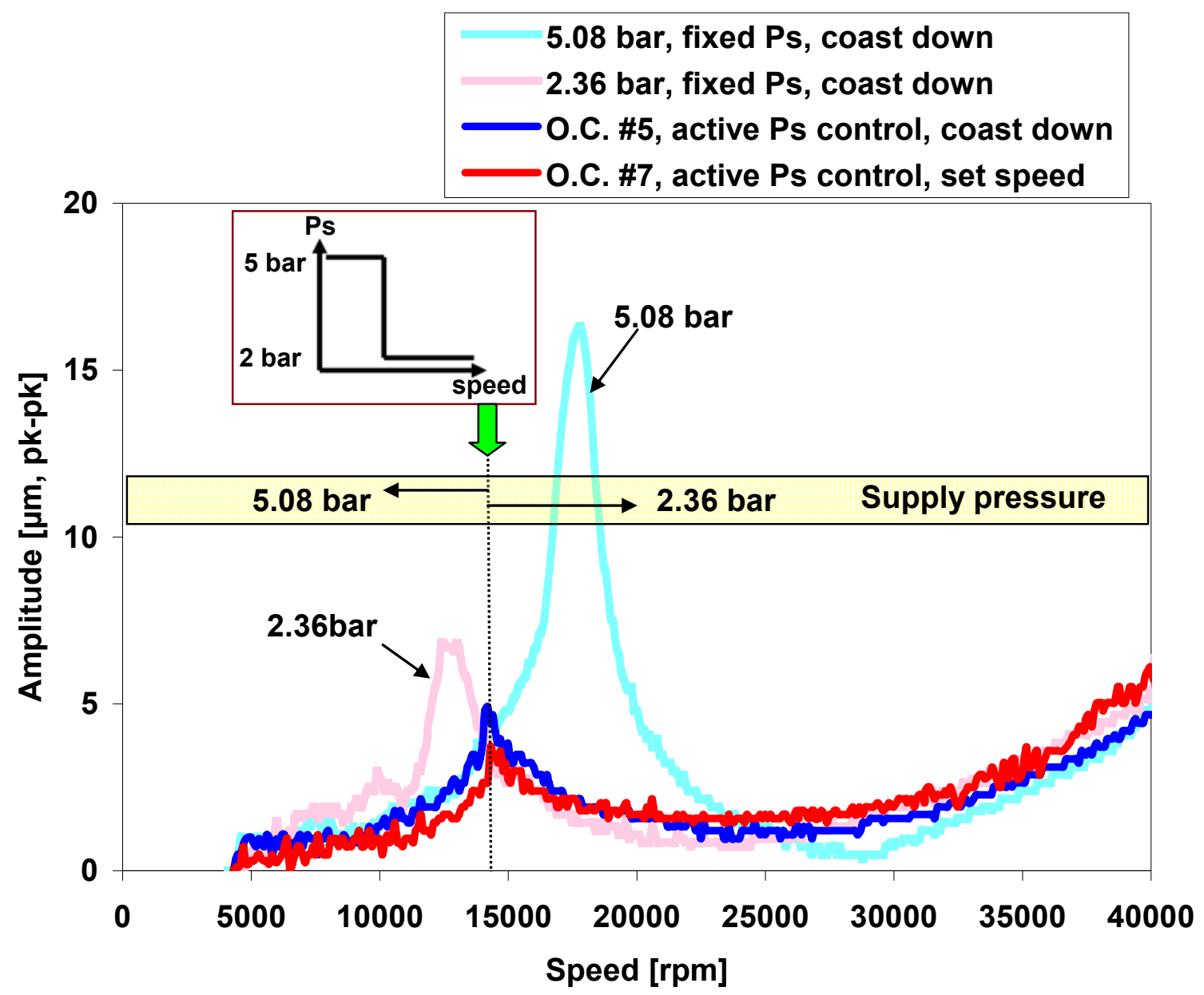

Fig. 17 Rotor synchronous response versus shaft speed. Right bearing horizontal direction (RH). Operating conditions (O.C.) \#5 and 7. Controller activated system. 


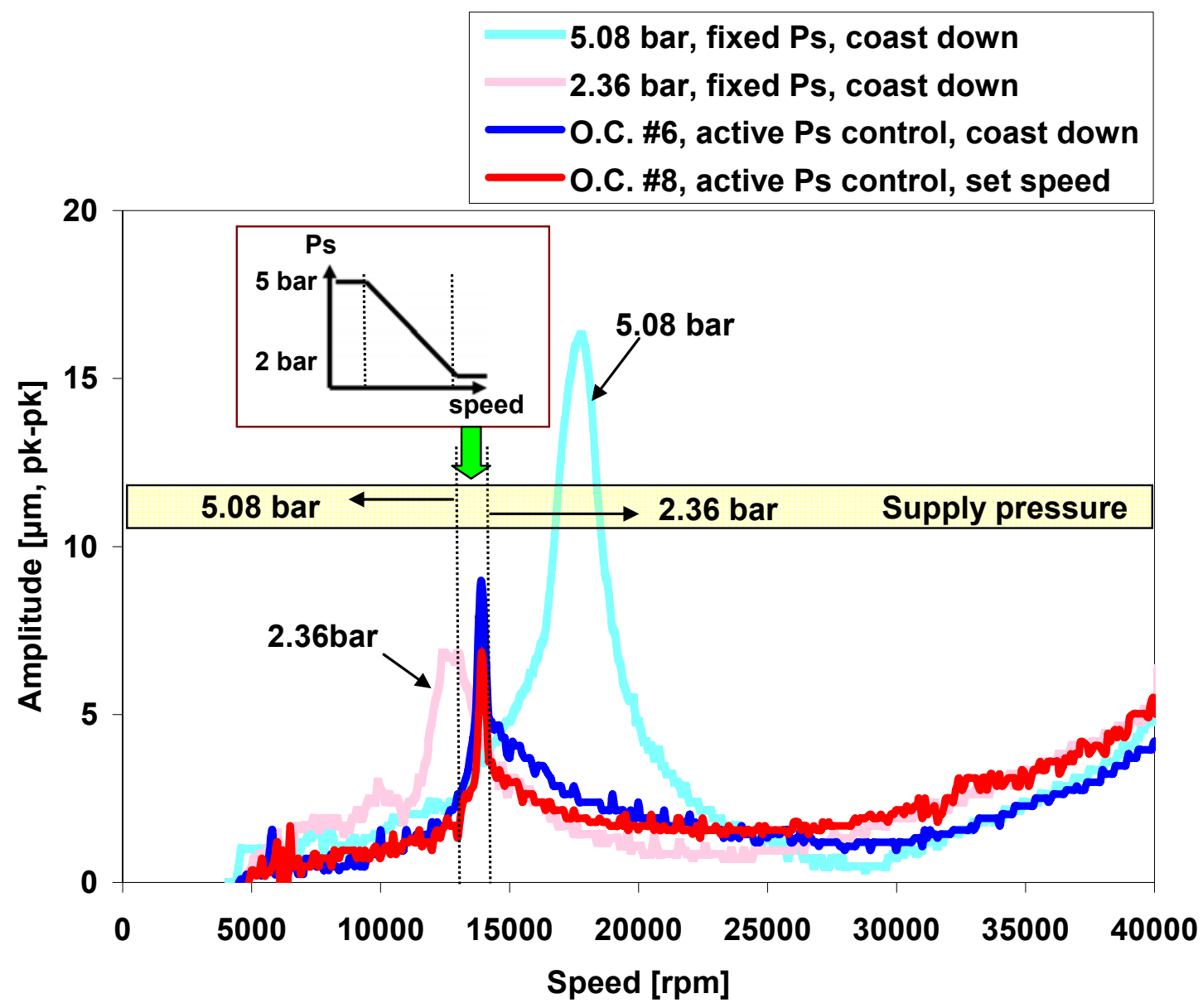

Fig. 18 Rotor synchronous response versus shaft speed. Right bearing horizontal direction (RH). Operating conditions (O.C.) \#6 and 8. Controller activated system. 


\section{PREDICTIONS OF ROTORDYNAMIC RESPONSE AND COMPARISON TO TEST RESULTS}

The rotordynamic analysis consists of modeling the test rotor with XLTRC $^{2}{ }^{\circledR}$ and prediction of the bearing force coefficients with TILTPADHGBC. Computational code TILTPADHGBC, developed by San Andrés [28], predicts the static and dynamic forced response of fixed or hydrostatic and hydrodynamic tilting pad gas.

Table 3 shows the representative radial clearances and preload for the test bearings, as used to obtain predictions. Recall Table 1 details the bearing dimensions. The dimensionless pad preload for the previous experiments reported in [10] is $30 \%$. Rotor speed coast-down tests in [10] deteriorated the pads' surfaces, thereby reducing the pad preload. Note that the radial clearances and preloads in Table 3 are representative only; Figure 6 shows the actual bearing clearances varying along the axial and circumferential directions.

Table 3 Representative clearance and preload for prediction of force coefficients in test bearings

\begin{tabular}{|c|c|c|}
\hline \multirow{2}{*}{ Bearing } & Radial pad clearance, & \multirow{2}{*}{ Pad preload } \\
\cline { 2 - 2 } & $C_{p}=R_{p}-R_{j}$ & \\
\hline Right & $38.0 \mu \mathrm{m}$ & $0.22(8.4 \mu \mathrm{m})$ \\
\hline Left & $44.5 \mu \mathrm{m}$ & $0.15(6.7 \mu \mathrm{m})$ \\
\hline
\end{tabular}

Figure 19 shows the 22 finite element structural model of the composite test rotor. Measured free-free natural frequencies and mode shapes validate closely the rotor structural model, see Ref. [29]. 


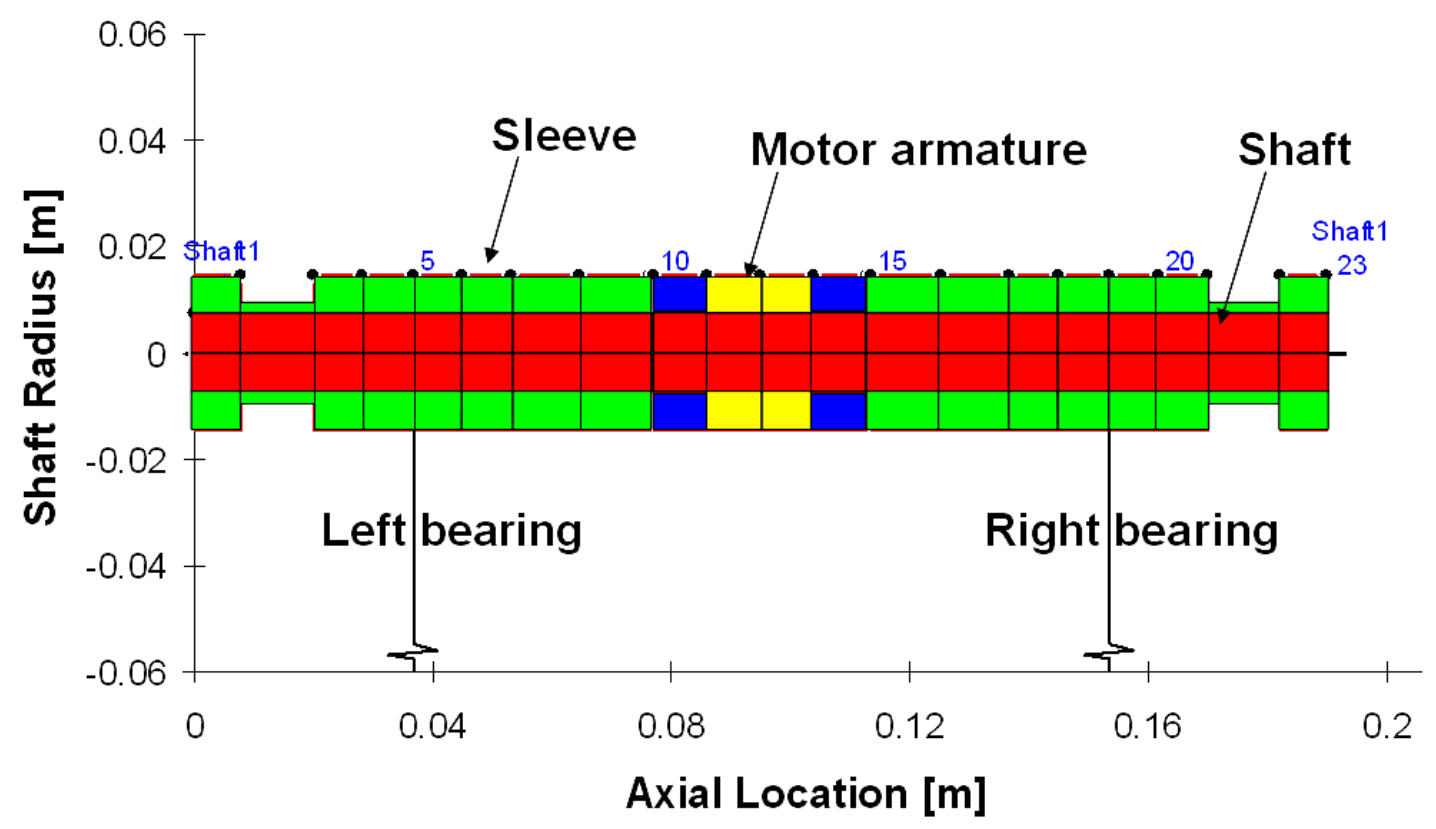

Fig. 19 Structural model of test rotor.

Figure 20 depicts the measured and predicted mass flow rates through the bearing for increasing supply pressures. Larger clearances on the left bearing render higher flow rates than for the right bearing. Imperfect sealing of the feed pressure chamber also causes discrepancies between the measured and predicted mass flow rates. Ref. [10] also reports similar observations. 


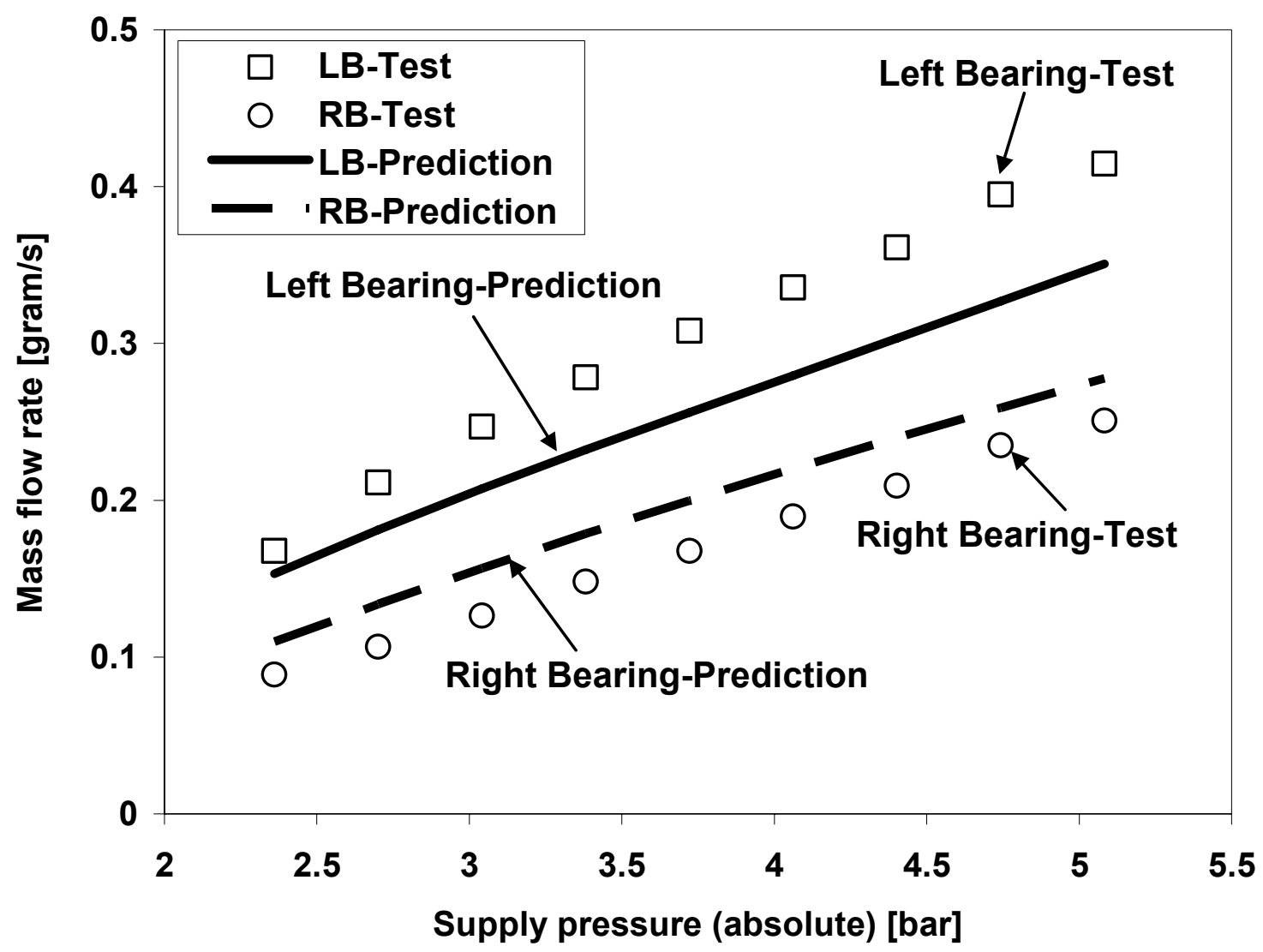

Fig. 20 Measured and predicted mass flow rates for test bearings versus supply pressure.

Predicted (synchronous) force coefficients for each supply pressure condition are incorporated into $\mathbf{X L T R C}^{2}{ }^{\circledR}$ for prediction of the rotor imbalance response. The eigenvalue analysis of the rotor-bearing system renders the natural frequencies and modal damping ratios, depicted in Figure 21 and Figure 23, respectively. Figure 21 shows the predicted damped natural frequency of the test rotor-bearing system for 5.08 bar absolute feed pressure. Figure 22 depicts the first two rigid body modes, corresponding with the critical speeds at $13.2 \mathrm{krpm}$ and $18.0 \mathrm{krpm}$ shown in Figure 21. The difference in force coefficients for the left and right bearings determines two rigid body conical modes; see Ref. [10]. Figure 23 depicts the predicted modal damping ratios for increasing feed pressures into the bearings. As the supply pressure increases, the modal damping ratios decrease. 


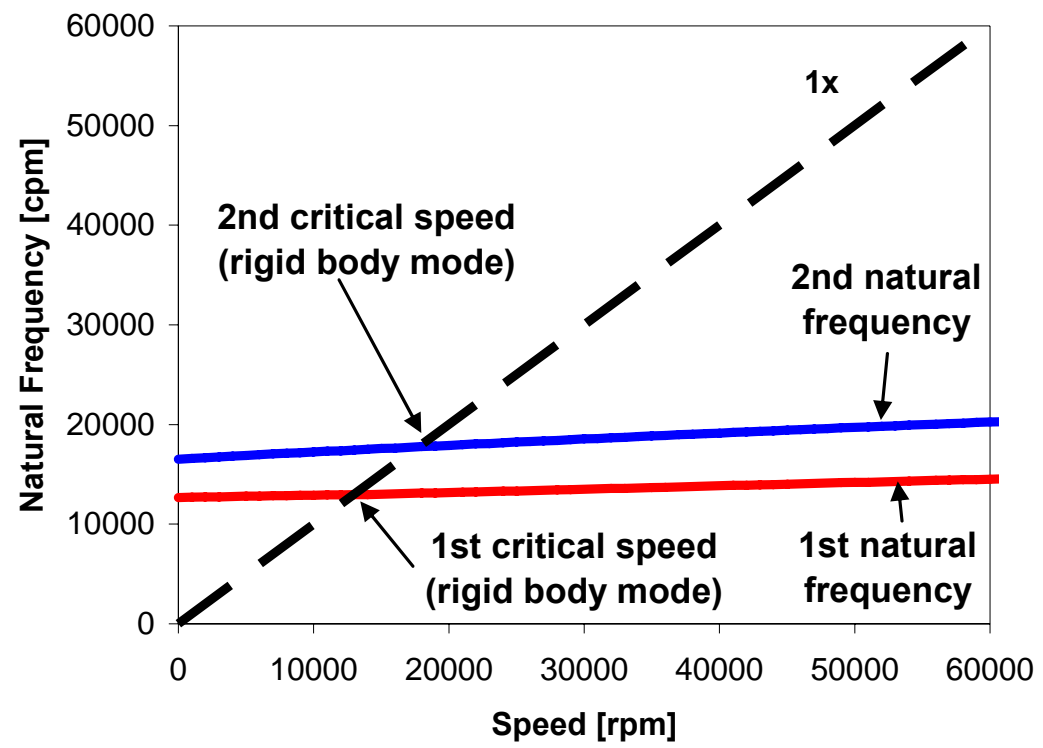

Fig. 21 Predicted damped natural frequency map of test rotor-bearing system. 5.08 bar feed pressure.

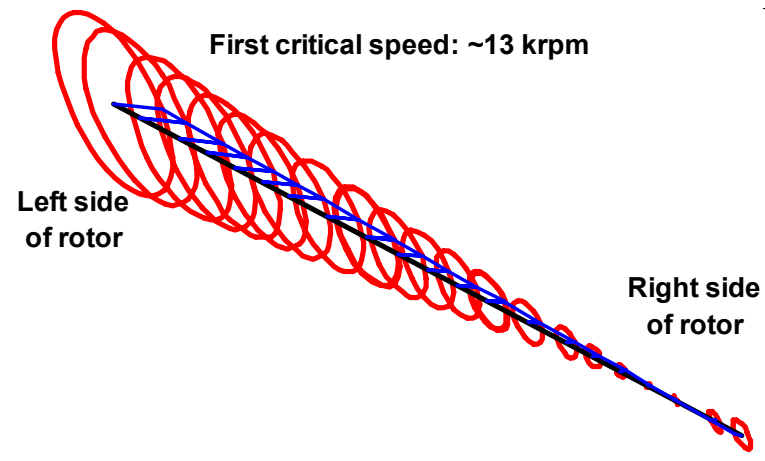

(a) First rigid body mode

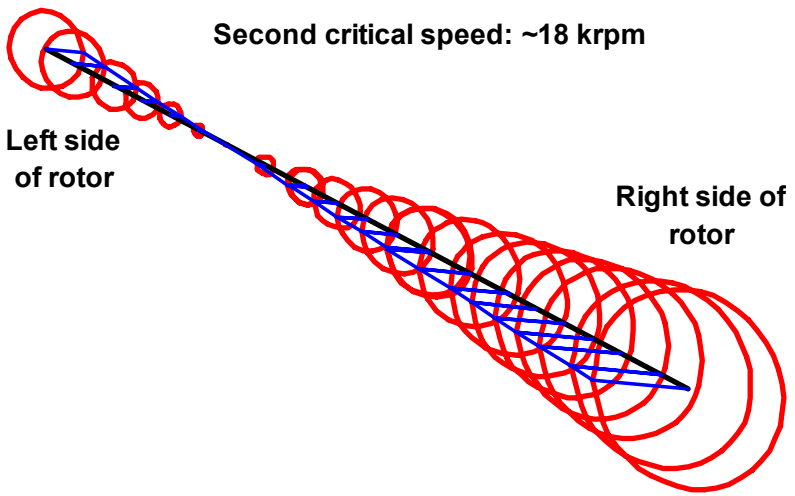

(b) Second rigid body mode

Fig. 22 Mode shapes of test rotor at critical speeds. 5.08 bar feed gas pressure. 


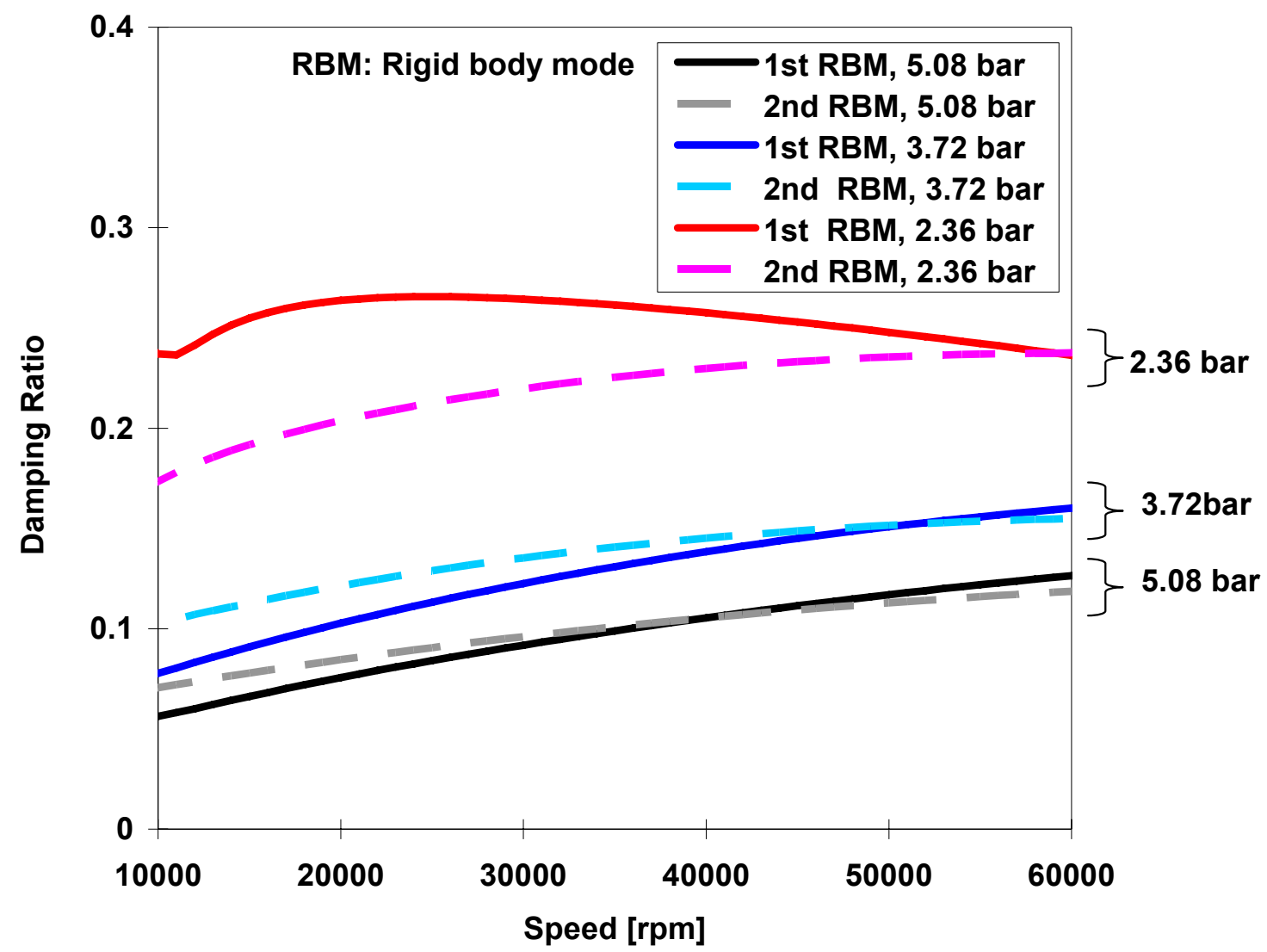

Fig. 23 Predicted damping ratios versus rotor speed for three feed pressures.

\section{Comparison between Predictions and Measured Imbalance Responses}

Imbalance Responses for Fixed Supply Pressures

Figure 24 shows the predicted and measured synchronous rotor imbalance response for 5.08 bar absolute feed pressure into the bearings. The rotor motion measurements are along the horizontal direction near the left and right bearings. Table 4 shows the imbalance masses used in the analysis, $0.028 \mathrm{gram} \cdot \mathrm{mm}$ and $0.565 \mathrm{gram} \cdot \mathrm{mm}$ at the left and right ends of the rotor, respectively. Notice that the actual rotor imbalance distribution is unknown. The values used for rotordynamic analysis derive from matching the peak amplitudes of rotor motion at the system critical speed. 
Table 4 Imbalance masses used for system response predictions

\begin{tabular}{|c|c|c|}
\hline $\begin{array}{c}\text { Location } \\
\text { (station \# in rotor model) }\end{array}$ & Amount & Phase difference \\
\hline Left end (1) & $0.028 \mathrm{gram} \cdot \mathrm{mm}$ & \multirow{2}{*}{$180^{\circ}$ out of phase } \\
\hline Right end (23) & $0.565 \mathrm{gram} \cdot \mathrm{mm}$ & \\
\hline
\end{tabular}

Figure 25 compares predicted and measured imbalance responses of the test rotor for increasing feed pressures. Figure 26 depicts the critical speeds of the test rotor-bearing system determined from predicted and measured rotor responses. For $P_{s}$ (supply pressure) $>3.5$ bar (absolute), the correlation of predictions to measurements is remarkable. However, as the supply pressure decreases, the test data shows higher critical speeds with smaller rotor motion amplitudes. This implies that the stiffness and damping coefficients of the test bearings are larger than the predicted values for low supply pressure conditions $\left(P_{s}<3.5\right.$ bar $)$.

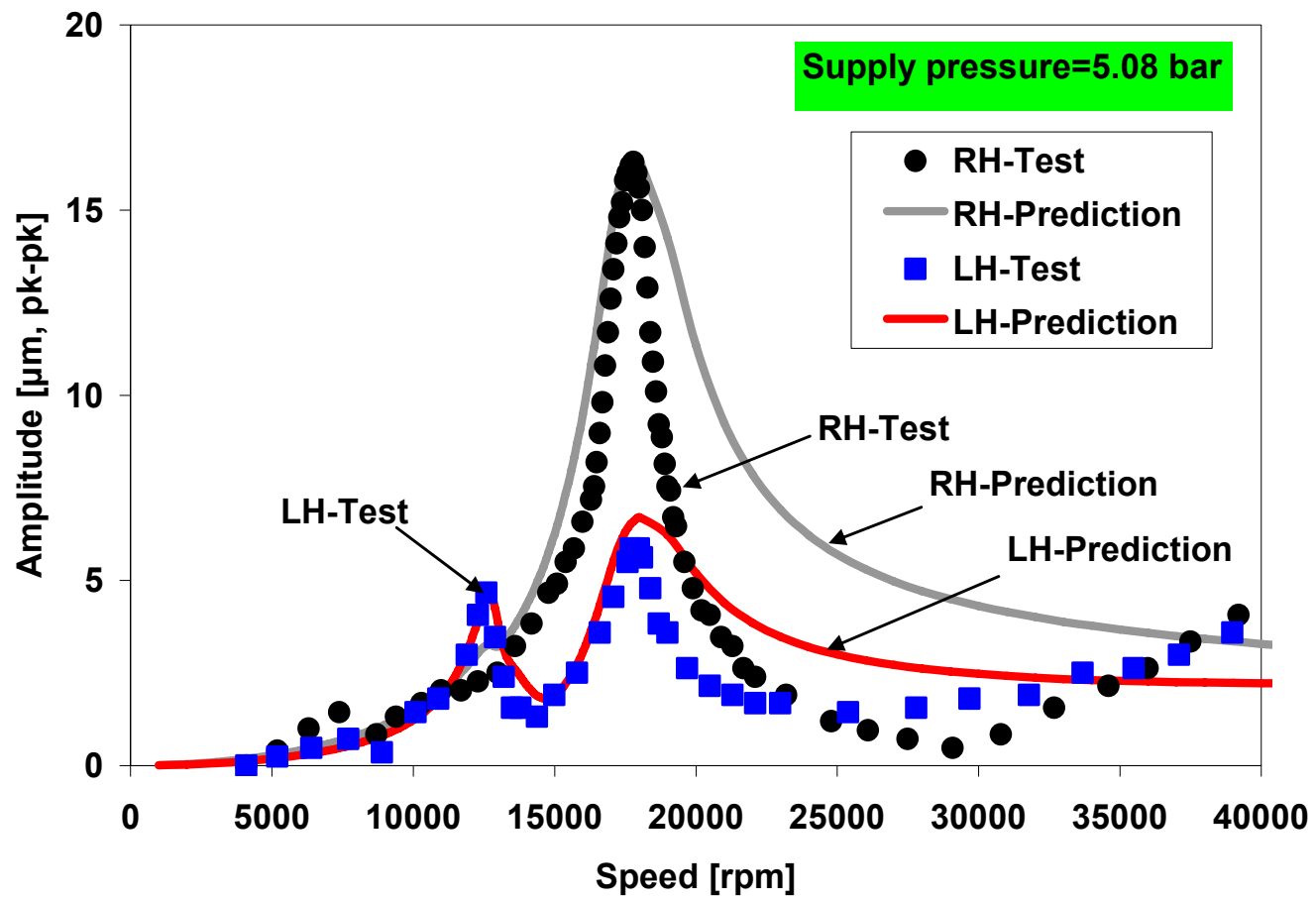

Fig. 24 Comparison of predicted and measured imbalance response of test rotor for supply pressure 5.08 bar (absolute). Right bearing horizontal (RH) and left bearing horizontal (LH) directions. 


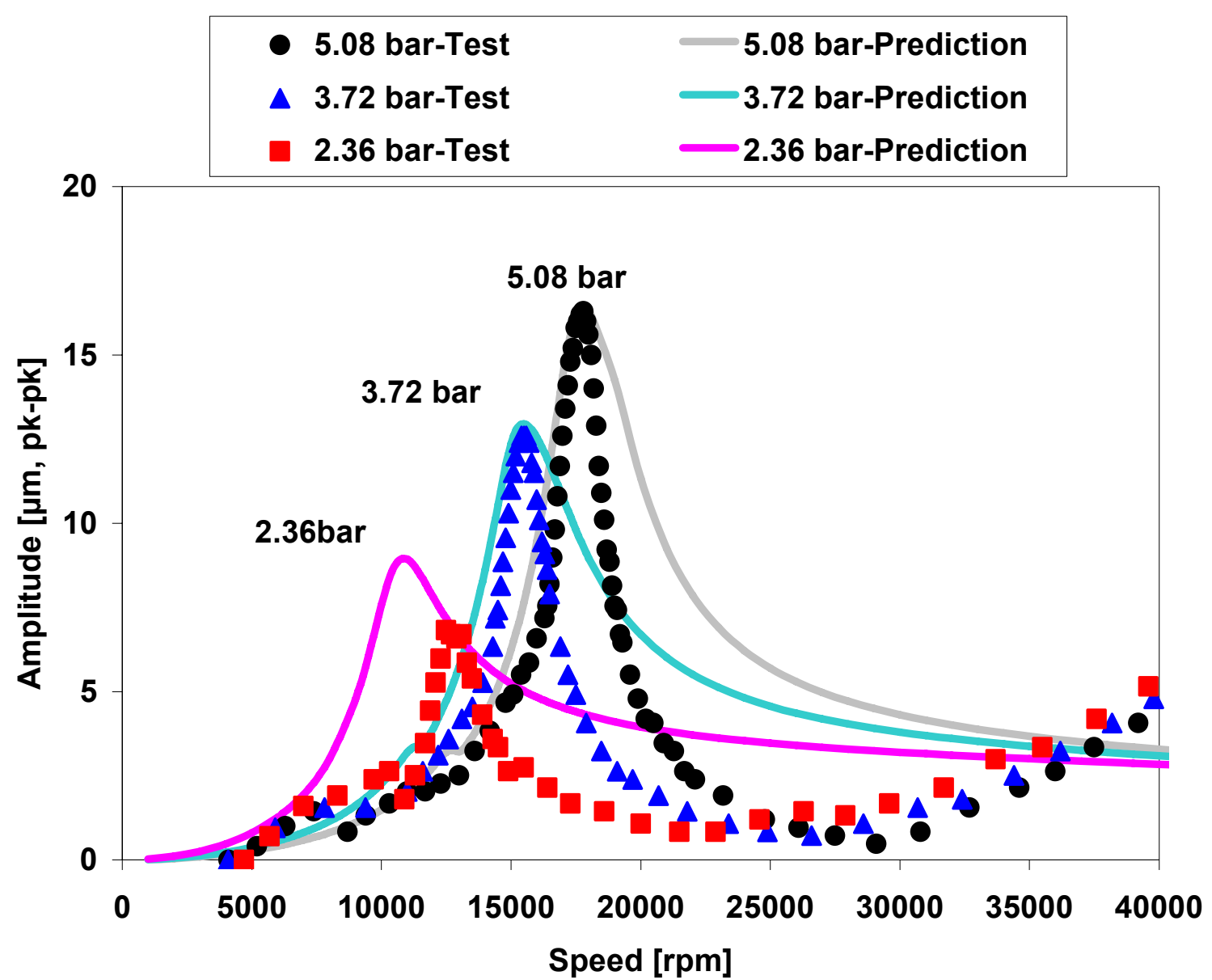

Fig. 25 Comparison of predicted and measured imbalance response of test rotor for increasing supply pressures. Right bearing horizontal direction (RH). 


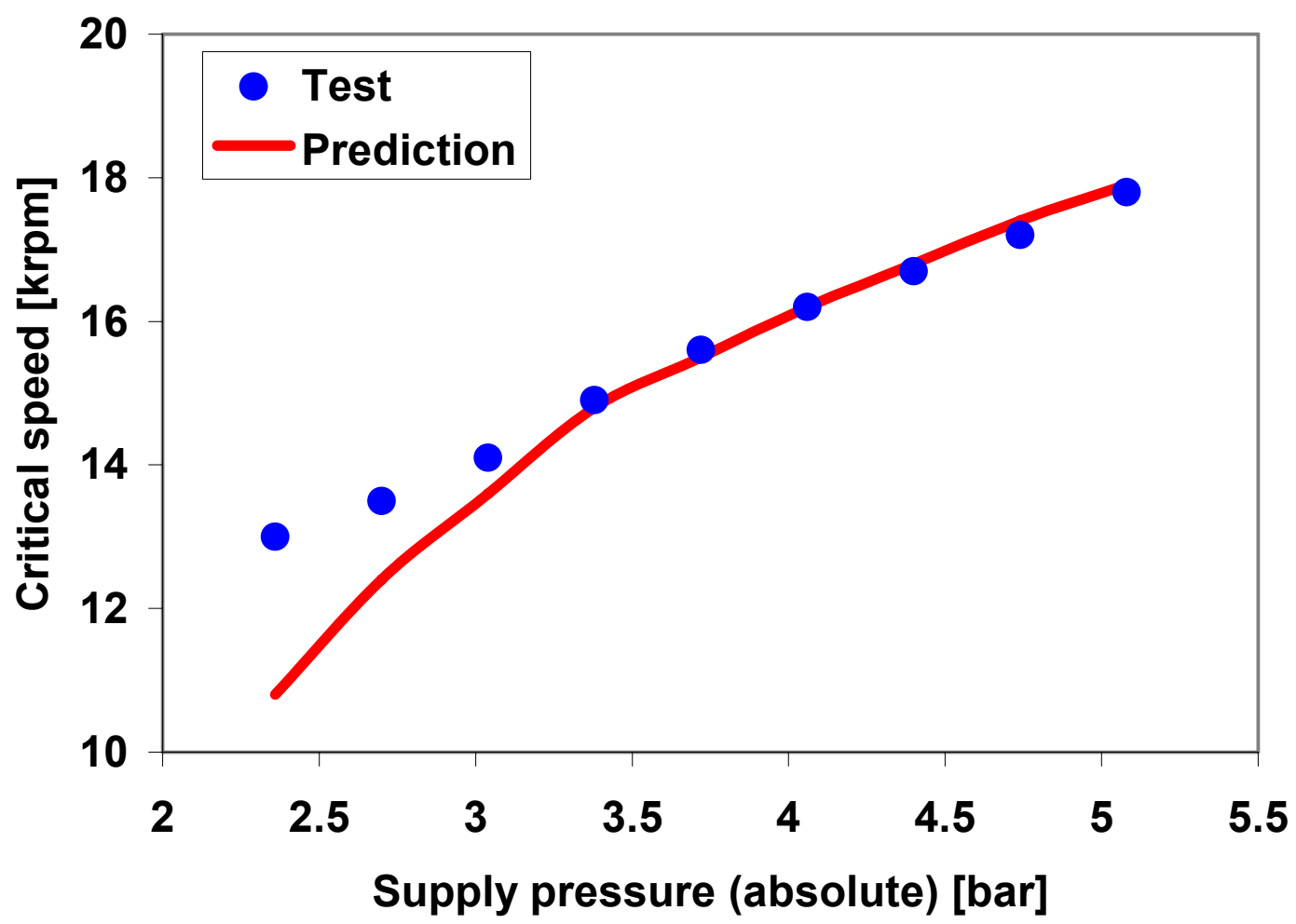

Fig. 26 Comparison of predicted and measured critical speeds of test rotor-bearing system for increasing supply pressures along right bearing horizontal direction (RH).

Predicted Rotor Responses for Cases with Controlled Supply Pressures

Figures 27 through 32 depict the predicted synchronous response to rotor imbalance for three different control methods of supply pressure into the bearings and comparisons to the test data. The predictions show a remarkable agreement within the rotor speed region of controlled supply pressure. Note that the rotor motion for operating condition \#4 shows much smaller peak amplitude while passing through the manually controlled supply pressure region. 


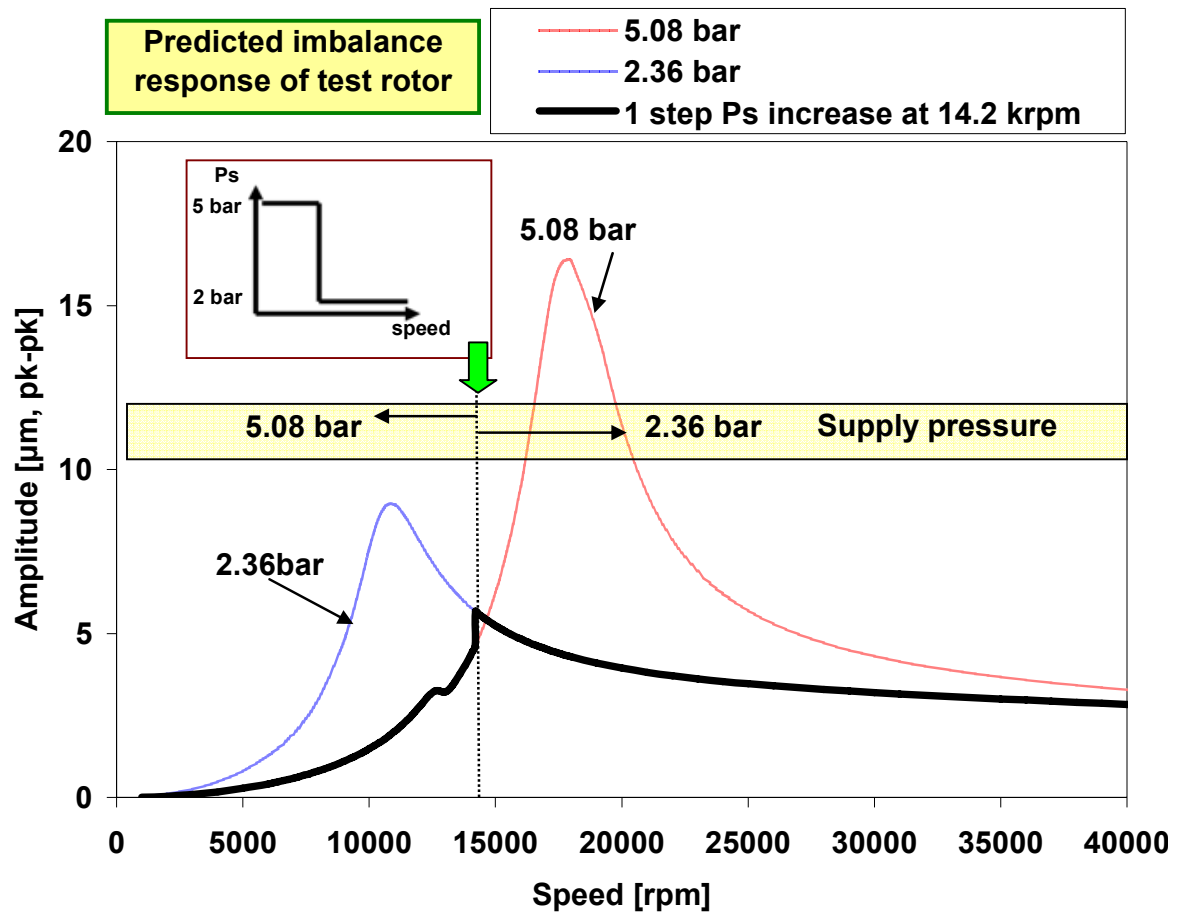

Fig. 27 Predicted imbalance response for one-step increase in supply pressure (2.36 bar) at $14.2 \mathrm{krpm}$. Right bearing horizontal direction ( $\mathrm{RH})$.

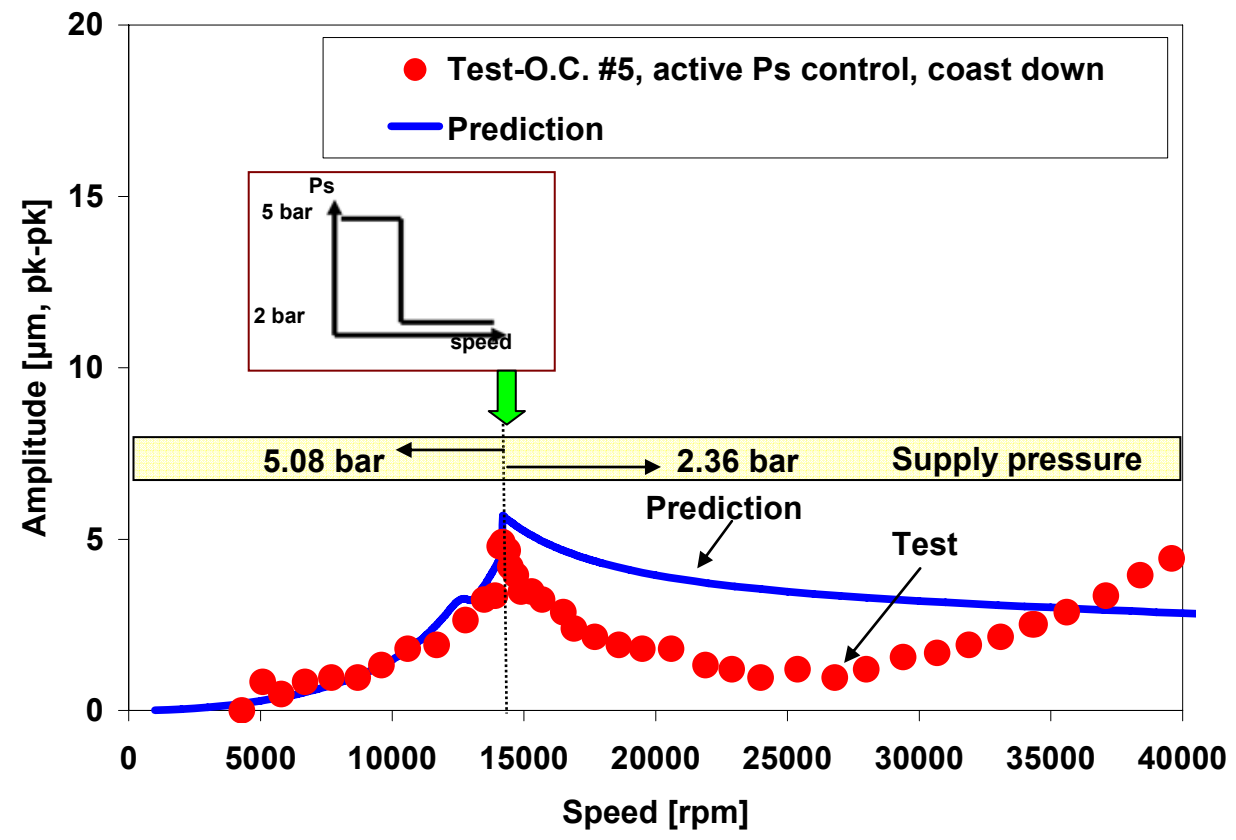

Fig. 28 Comparison of predicted and measured imbalance responses. Measurement for operating condition (O.C.) \#5 and prediction for one-step increase in supply pressure (2.36 bar) at $14.2 \mathrm{krpm}$. Right bearing horizontal direction ( $\mathrm{RH})$. 


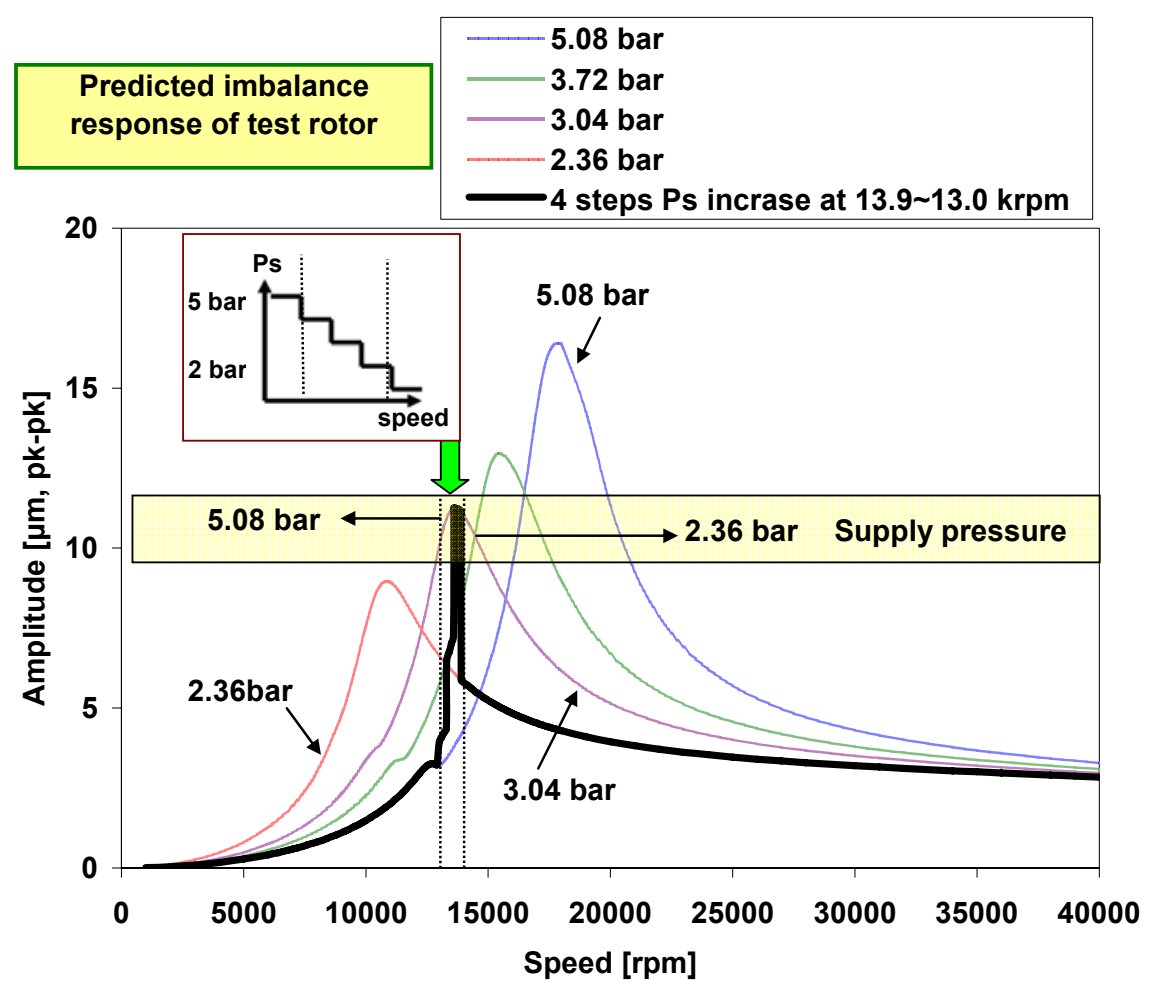

Fig. 29 Predicted imbalance response for four-step increase in supply pressure (2.36 bar) from $13.9 \mathrm{krpm}$ to $13.0 \mathrm{krpm}$. Right bearing horizontal direction (RH).

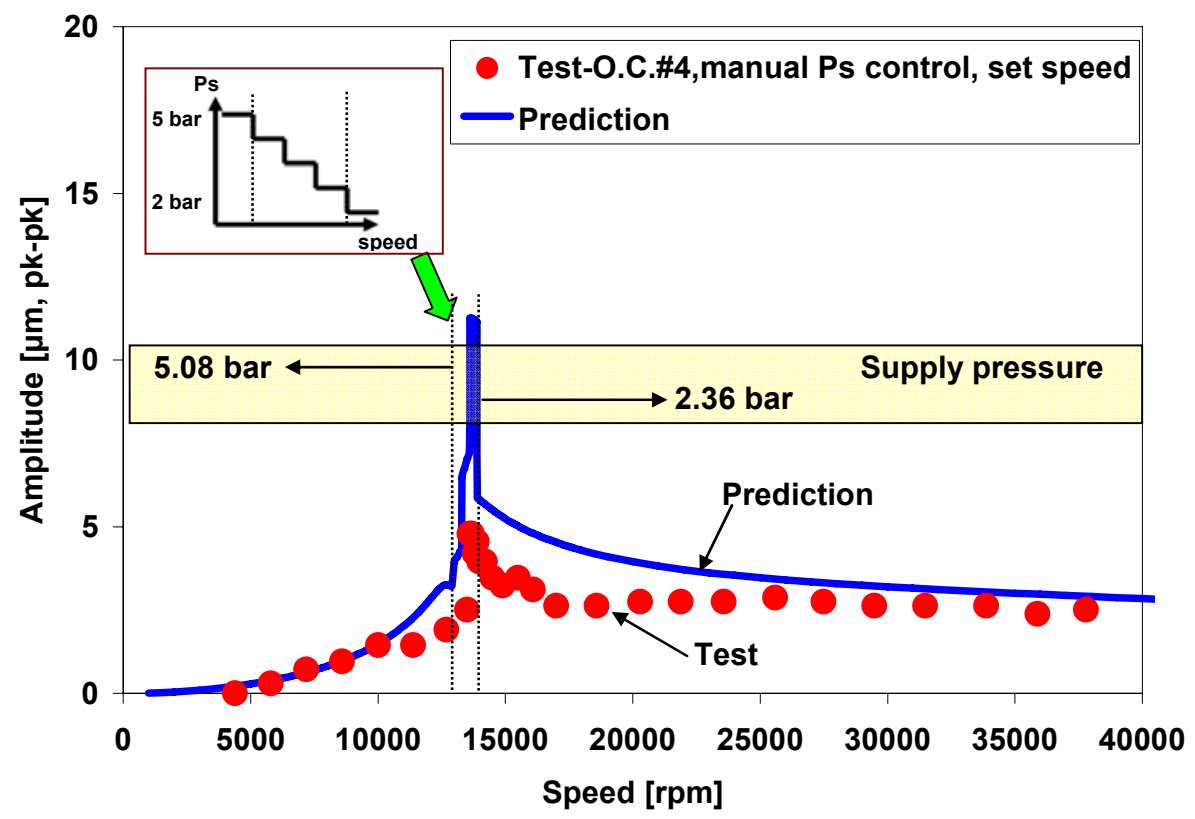

Fig. 30 Comparison of predicted and measured imbalance responses. Measurement for operating condition (O.C.) \#4 and prediction for four-step increase in supply pressure (2.36 bar) from $13.9 \mathrm{krpm}$ to $13.0 \mathrm{krpm}$. Right bearing horizontal direction (RH). 


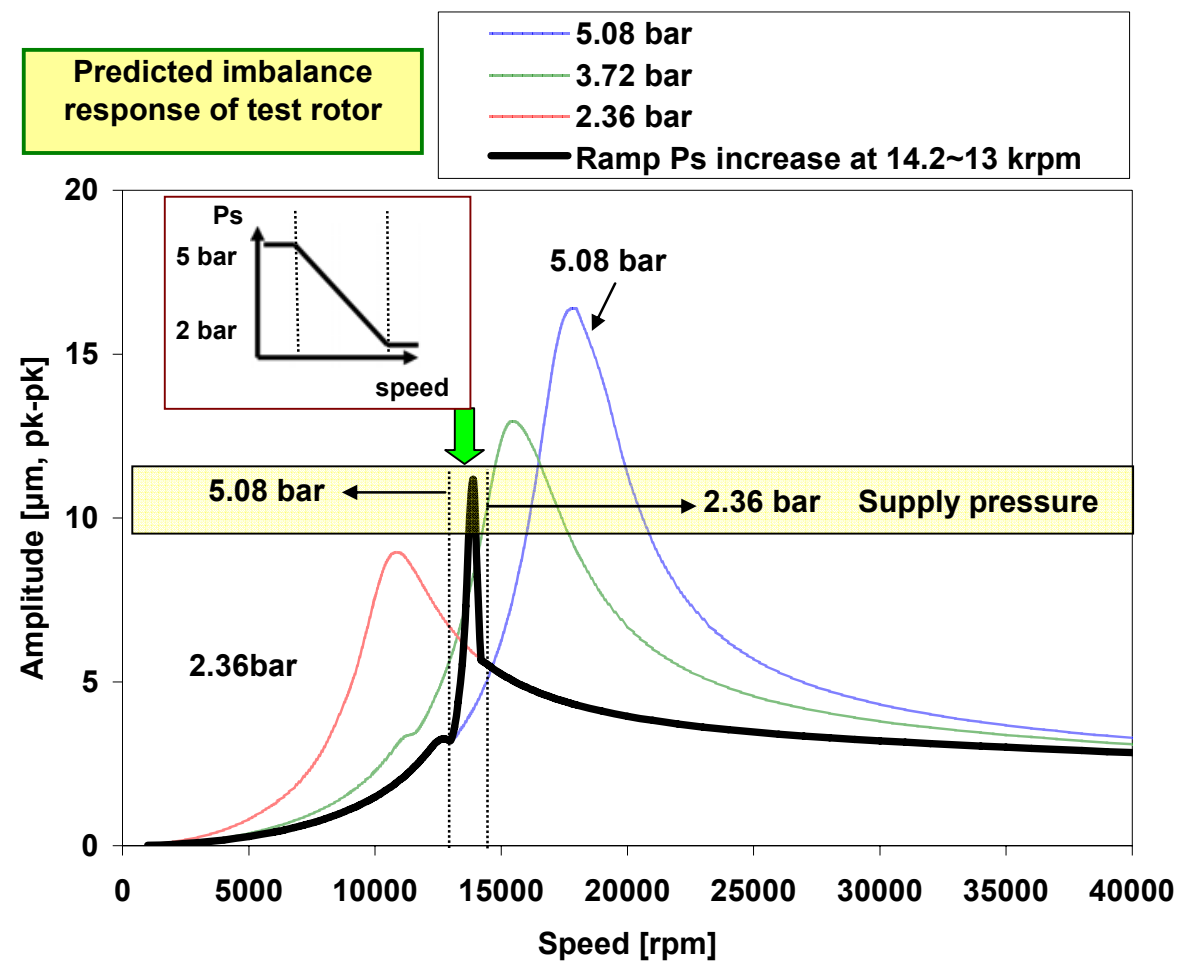

Fig. 31 Predicted imbalance response for ramp increase in supply pressure (2.36 bar) from $14.2 \mathrm{krpm}$ to $13.0 \mathrm{krpm}$. Right bearing horizontal direction (RH).

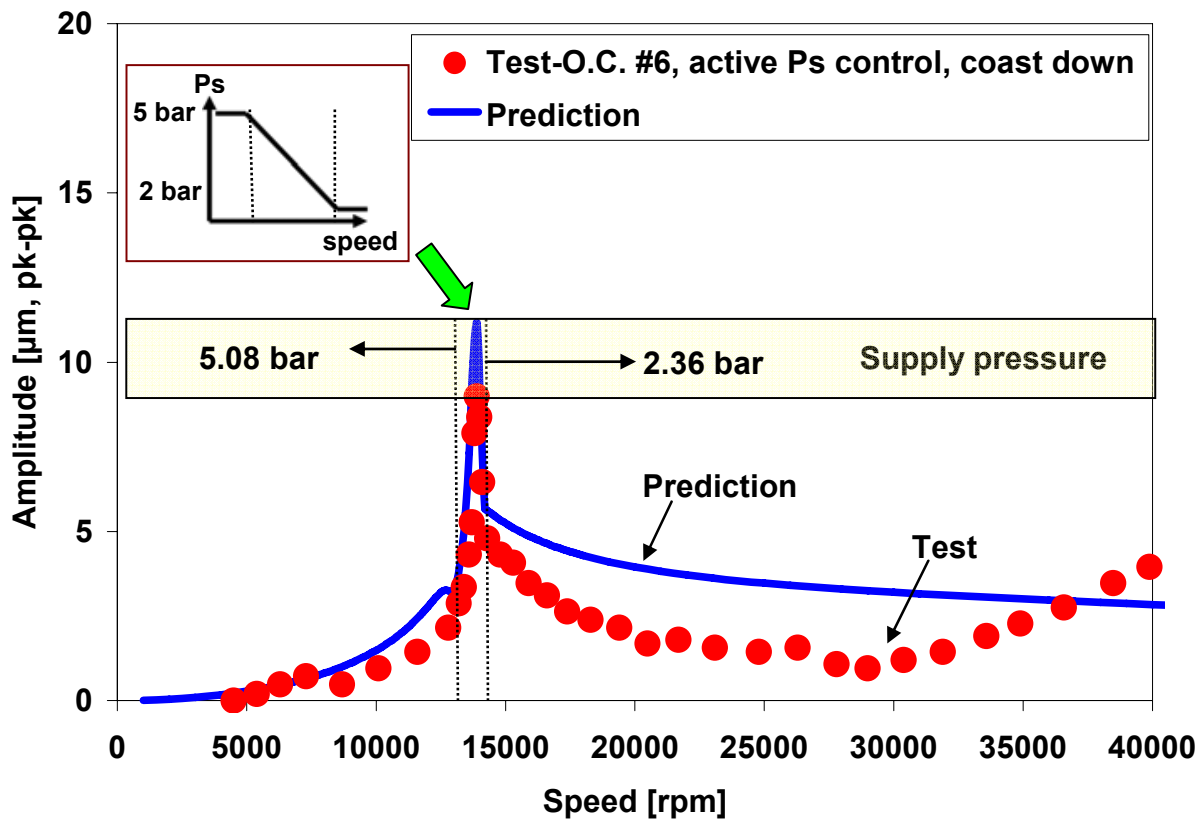

Fig. 32 Comparison of predicted and measured imbalance responses. Measurement for operating condition (O.C.) \#6 and prediction for ramp increase in supply pressure (2.36 bar) from $14.2 \mathrm{krpm}$ to $13.0 \mathrm{krpm}$. Right bearing horizontal direction (RH). 


\section{CONCLUSIONS AND RECOMMENDATIONS}

Earlier test results with hybrid flexure pivot gas bearings [10] show that external pressurization stiffens the bearings, thereby increasing the system critical speeds. Furthermore, the measurements evidence that external pressurization into the test gas bearings is not necessary for operation beyond the critical speed of the rotor-bearing system. In particular, the measurements of rotor motion during rotor speed coast downs while manually controlling the feed pressure show elimination of critical speeds with smooth operation over an entire operating speed range. The present work continues prior art [10], and provides further rotordynamic demonstrations using a device to control the supply pressure into the hybrid gas bearings.

The test bearings comprise four pads, offset $60 \%$, and $1 \mathrm{~mm}$ feeding holes in each pad. The bearings have uneven pads surfaces due to former exhaustive coast-down demonstrations, thereby producing dissimilar clearance along the axial and circumferential directions. An inexpensive electro-pneumatic air regulator controls the air supply pressure into the bearings. The feed pressure needs to increase as the rotor speed decreases over a relatively narrow speed region. Open and closed loop control systems of supply pressure into the test bearings are set up to relate the rotor speed to the supply pressure. Rotordynamic response measurements are conducted for eight test operating conditions based on various feeding pressure control methods and preset rotor speed regions.

Rotor coast down speed tests with constant feed pressure determine the rotor speed region for supply pressure control. The demonstrations show that step jump and multiple step-wise increases in supply pressure noticeably lessen the rotor synchronous response amplitudes while crossing the system critical speed. However, for a uniformly increasing (ramp) supply pressure condition, the rotor-bearing system encounters a sudden critical speed over the narrow preset speed region, thus showing a notable peak in the rotor synchronous response. 
A FE rotordynamic analysis models the test rotor and integrates predicted synchronous bearing force coefficients. Linear rotordynamic predictions for cases with controlled supply pressures correlate very well with the test data. The experiments validate the computational model even when the bearings are known to be severely worn.

In practice, uneven and dissimilar bearing surface conditions affect the bearing force coefficients, thereby offering different critical speeds along the horizontal and vertical directions. To entirely eliminate high rotor amplitudes for each direction along the rotor, independent control of supply pressure for each feeding hole is preferable.

Flexure pivot tilting pad gas bearings are mechanically complex and costlier than other types of gas bearings. However, they provide superior stability and dynamic forced performance over other bearing configurations experimented with earlier, namely threelobe bearings [26] and Rayleigh-step bearings [27]. The current work serves to advance hybrid gas bearing applications for use in high performance MTM and further demonstrates the reliability of the test bearings even when operating with worn pad surfaces. 


\section{REFERENCES}

[1] Kolanowski, B. F., 2004, Guide to Microturbines, Fairmont Press, Inc., Lilburn.

[2] Ohkubo, Y., 2005, “Outlook on Gas Turbine,” R\&D Review of Toyota Central R\&D Labs. Inc., 41, pp.1-11.

[3] Hamilton, S. L., 2003, The Handbook of Microturbine Generators, Penn Well, Tulsa, OK.

[4] Hamrock, B. J., 1994, Fundamentals of Fluid Film Lubrication, McGraw-Hill, New York.

[5] Fleming D. P., Cunningham, R. E., and Anderson, W. J., 1968, "Stability Anaysis for Unloaded Externally Pressurized Gas-lubricated Bearings with Journal Rotation," NASA TN D-4934.

[6] Lucero, J. M., and DellaCorte, C., 2004, "Oil-Free Rotor Support Technologies for Long Life, Closed Cycle Brayton Turbines," Proc. 2nd International Energy Conversion Engineering Conference, Providence, RI, AIAA 2004-5720.

[7] Childs, D., 1993, Turbomachinery Rotordynamics: Phenomena, Modeling, and Analysis, John Wiley \& Sons, New York.

[8] Zeidan, F., 1992, “Developments in Fluid Film Bearing Technology,” Turbo. Int., 9, pp. 24-31.

[9] Zhu, X., and San Andrés, L., 2004, "Rotordynamic Performance of Flexure Pivot Hydrostatic Gas Bearings for Oil-Free Turbomachinery," ASME paper GT 2004-53621. ASME J. Eng. Gas Turbines Power (to be published)

[10] San Andrés, L, and Ryu, K., 2007, Flexure Pivot Tilting Pad Hybrid Gas Bearings: Operation with Worn Clearances and Two Load-Pad Configurations," ASME paper GT2007-27127. ASME J. Eng. Gas Turbines Power (to be published)

[11] Isomura, K., Tanaka, S., Togo, S., and Esashi, M., 2005, "Development of HighSpeed Micro-Gas Bearings for Three-Dimensional Micro-Turbo Machines," J. Micromech. Microeng., 15, pp. 222-227.

[12] American Petroleum Institute, 2004, API 610, Centrifugal Pumps for Petroleum, Petrochemical and Natural Gas Industries, Washington DC. 
[13] American Petroleum Institute, 2003, API 617, Axial and Centrifugal Compressors and Turboexpanders for Petroleum, Chemical and Gas Industry Services, Washington DC.

[14] Nagaya, K., Takeda, S., Tsukui, Y., and Kumaido, T., 1987, “Active Control Method for Passing Through Critical Speeds of Rotating Shafts by Changing Stiffnesses of the Supports with Use of Memory Metals," J. Sound Vib., 113, pp. 307-315.

[15] Santos, I. F., 1995, "On the Adjusting of the Dynamic Coefficients of Tilting-Pad Journal Bearings,” STLE Tribol. Trans., 3, pp. 700-706.

[16] Zeidan, F. Y., San Andrés, L., and Vance. J. M., 1996, "Design and Application of Squeeze Film Dampers in Rotating Machinery," Proc. 25th Turbomachinery Symposium, Houston, TX, pp. 169-188.

[17] Bonneau, O., and Frene, J., 1997, "Non-linear Behavior of a Flexible Shaft Partly Supported by a Squeeze Film Damper," Wear, 206, pp. 244-250.

[18] Zarzour, M., and Vance, J., 2000, "Experimental Evaluation of a Metal Mesh Bearing Damper,” ASME J. Eng. Gas Turbines Power, 122, pp. 326-329.

[19] Palazzolo, A. B., Jagannathan, S., Kascak, A. F., Montague, G. T., and Kiraly, L. J., 1993, "Hybrid Active Vibration Control of Rotorbearing System Using Piezoelectric Actuators," ASME J. Vibr. Acoust., 115, pp. 111-119.

[20] Rustighi, E., 2004, "Dynamics of Rotating Machinery: Analysis, Identification and Control," Ph.D thesis, University of Pisa, Italy.

[21] Zhou, S. and Shi, J., 2001, "Active Balancing and Vibration Control of Rotating Machinery: A Survey,” Shock Vib. Dig., 33, pp. 361-371.

[22] Rho, B. H. and Kim, K. W., 2002, "Effect of Active Control Bearing on Unbalance Response of a Rotor-Bearing System," J. KSTLE, 18, pp. 99-104.

[23] Qui, J., Tani, J., and Kwon, T., 2003, "Control of Self-Excited Vibration of a Rotor System with Active Gas Bearings,” ASME J. Vibr. Acoust.,, 125, pp. 328-334.

[24] Santos, I. F., and Scalabrin, A., 2003, "Control System Design for Active Lubrication with Theoretical and Experimental Examples," ASME J. Eng. Gas Turbines Power, 125, pp. 75-80

[25] Bently, D. E., Grant, J. W., and Hanifan, P. C., 2000, "Active Controlled Hydrostatic Bearings for a New Generation of Machines," ASME paper 2000-GT-354. 
[26] Wilde, D. A., and San Andrés, L., 2006, "Experimental Response of Simple Gas Hybrid Bearings for Oil-Free Turbomachinery," ASME J. Eng. Gas Turbines Power, 128, pp. 626-633.

[27] Zhu, X., and San Andrés, L., 2005, "Experimental Response of a Rotor Supported on Rayleigh Step Gas Bearings,” ASME Paper GT 2005-68296.

[28] San Andrés, L., 2006, "Hybrid Flexure Pivot-Tilting Pad Gas Bearings: Analysis and Experimental Validation,” ASME J. Tribol., 128, pp. 551-558.

[29] San Andrés, L., and Ryu, K., 2006, "Test Results for Load-On-Pad and LoadBetween-Pad Hybrid Flexure Pivot Tilting Pad Gas Bearings," TL-B\&C-1-06, Turbomachinery Laboratory Research Report, Texas A\&M University, College Station. 


\section{APPENDIX A PREDICTED BEARING STIFFNESS AND DAMPING FORCE COEFFICIENTS}

Figures A.1 and A.2 depict the predicted static journal eccentricity and attitude angle for the right bearing as rotor speed decreases for step jump, multiple step-wise, and ramp increases in supply pressure. Ref.[10] details the effect of feed pressure on the static and dynamic bearing force coefficients, and journal eccentricities and attitude angles. The static load on each bearing is $4.042 \mathrm{~N}$. Note that the maximum dimensionless eccentricity is 0.78 for hydrodynamic operation and low rotor speed conditions. High supply pressures into the bearings render smaller journal eccentricities and attitude angles.

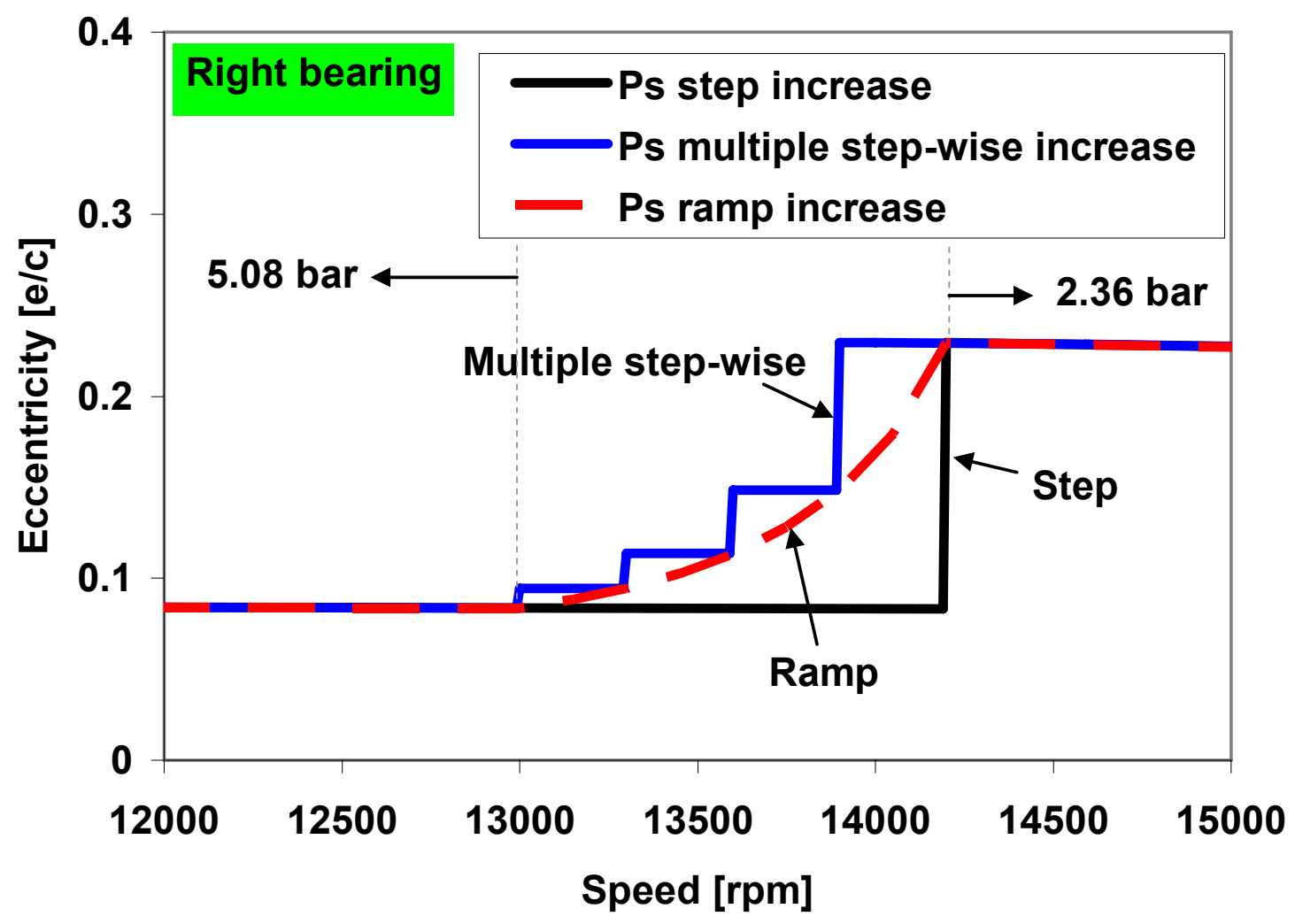

Fig. A.1 Predicted static journal eccentricity for step jump, multiple step-wise, and ramp increase in supply pressure. Static load $W=4.04 \mathrm{~N}$. 


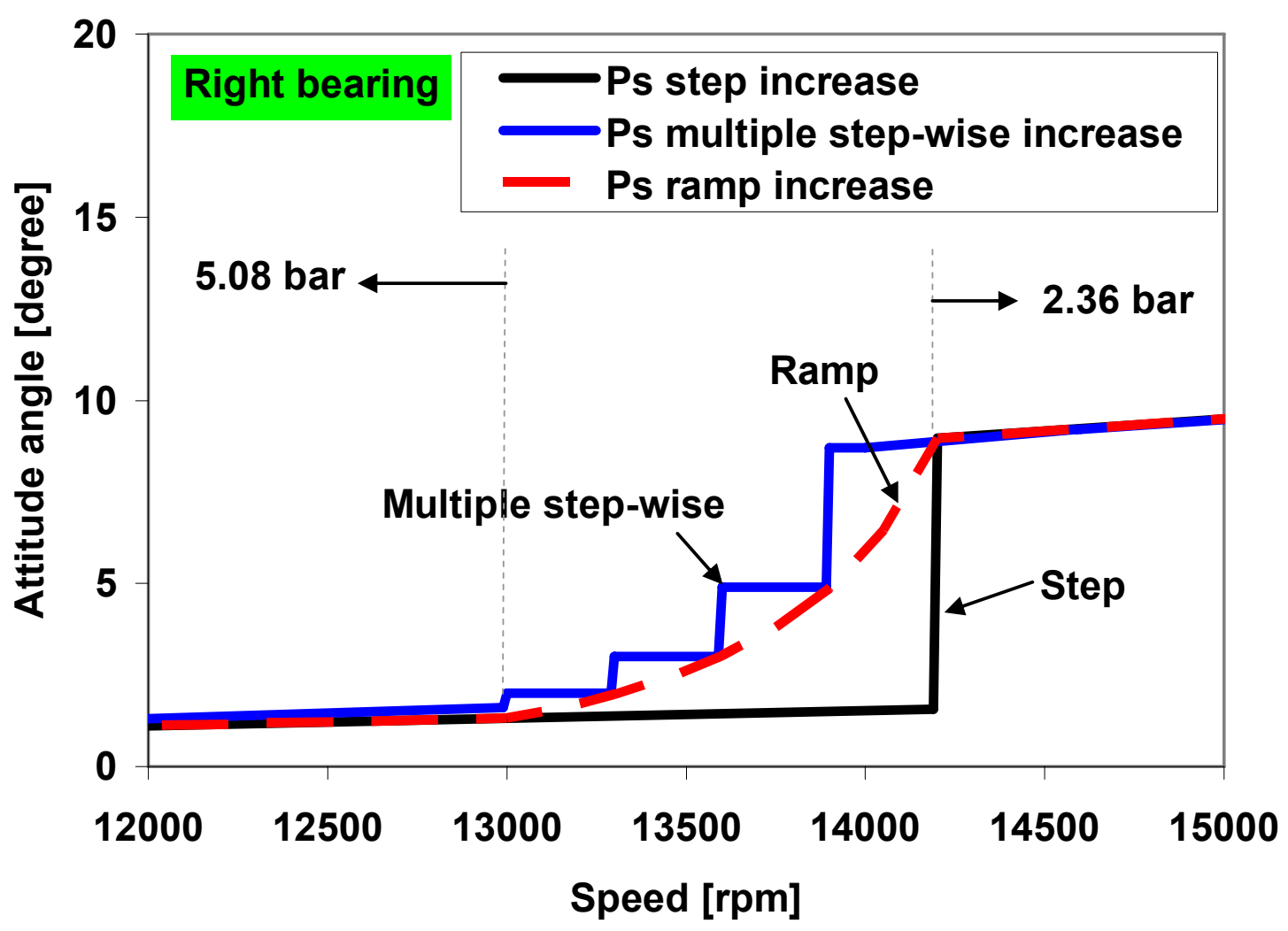

Fig. A.2 Predicted attitude angle for step jump, multiple step-wise, and ramp increase in supply pressure. Static load $W=4.04 \mathrm{~N}$.

Figures A.3 and A.4 depict the synchronous direct and cross-coupled stiffness and damping coefficients for a step jump increase in supply pressure. A lower supply pressure offers less direct stiffnesses and higher damping coefficients. Cross-coupled components for both coefficients are much smaller than direct components. For the direct stiffnesses and damping coefficients, abrupt changes occur when the supply pressure jumps.

Figures A.5 and A.6 compare the direct stiffness and damping coefficients for step jump, multiple step-wise, and ramp increase in supply pressure. The direct stiffnesses increase in proportion to the supply pressure, as depicted in Figure 11; whereas, the damping coefficients show a decrease with supply pressure. 


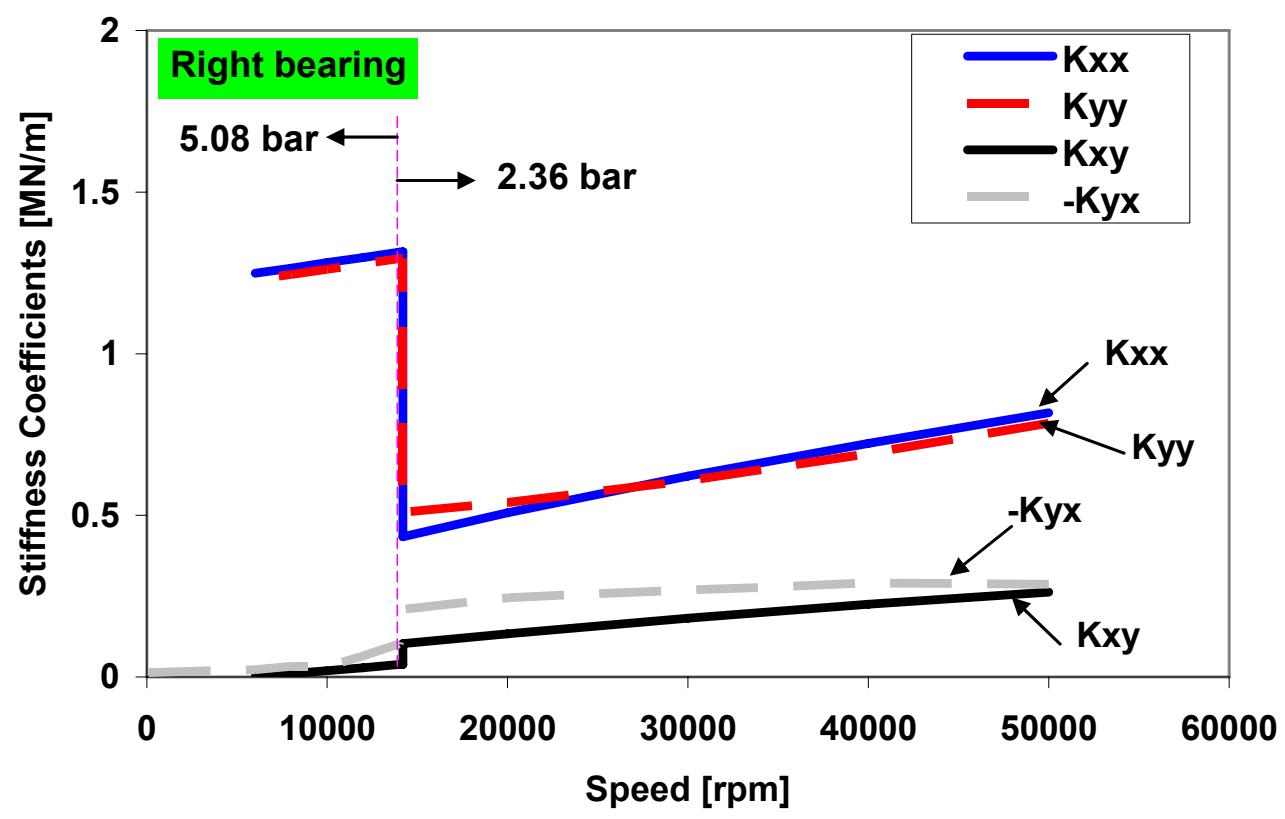

Fig. A.3 Predicted synchronous stiffnesses vs. speed. Right bearing. Step jump increase in supply pressure. Supply pressure increases at $14.2 \mathrm{krpm}$ from 2.36 bar to 5.08 bar (absolute).

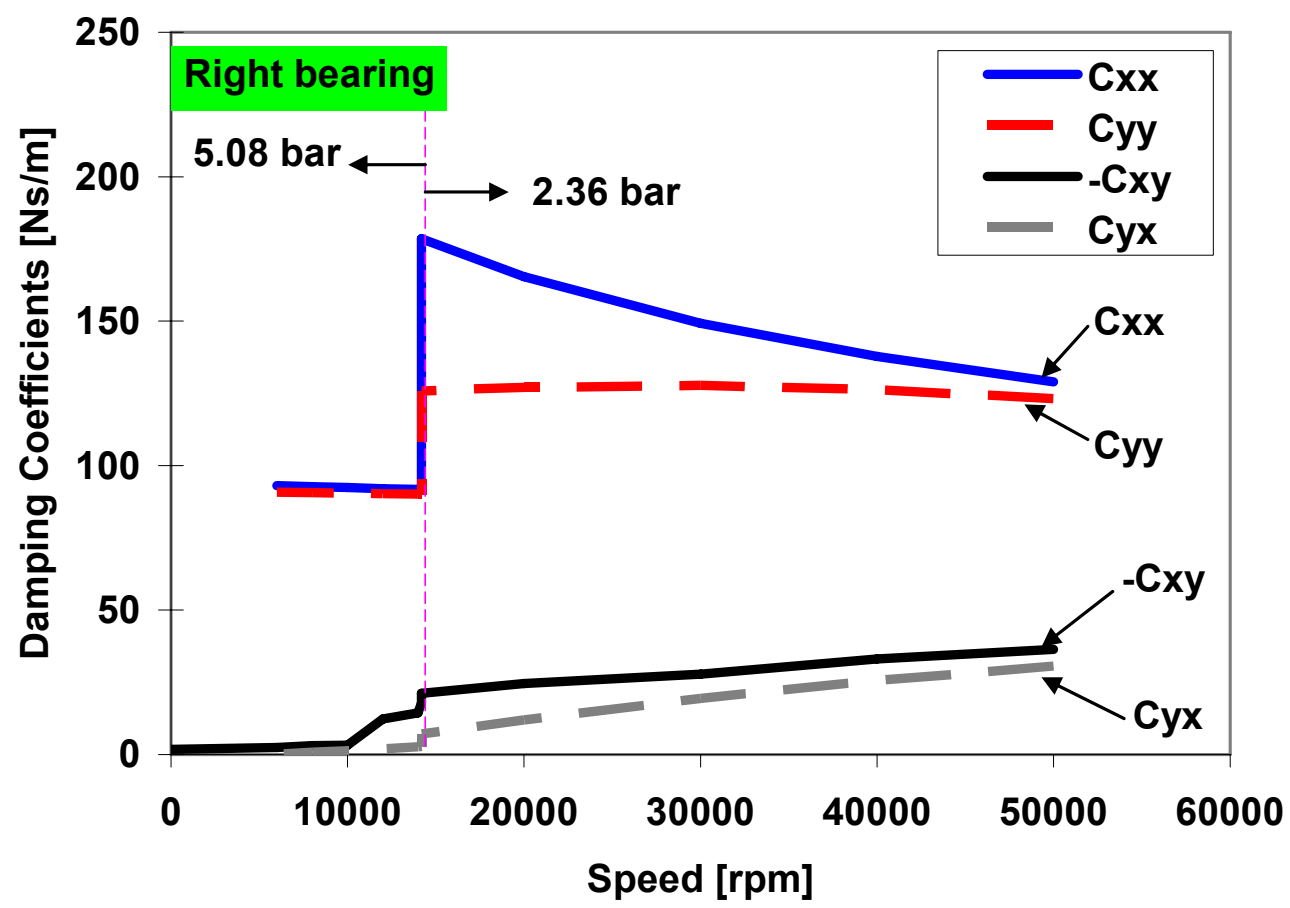

Fig. A.4 Predicted synchronous damping coefficients vs. speed. Right bearing. Step jump increase in supply pressure. Supply pressure increases at $14.2 \mathrm{krpm}$ from 2.36 bar to 5.08 bar (absolute). 


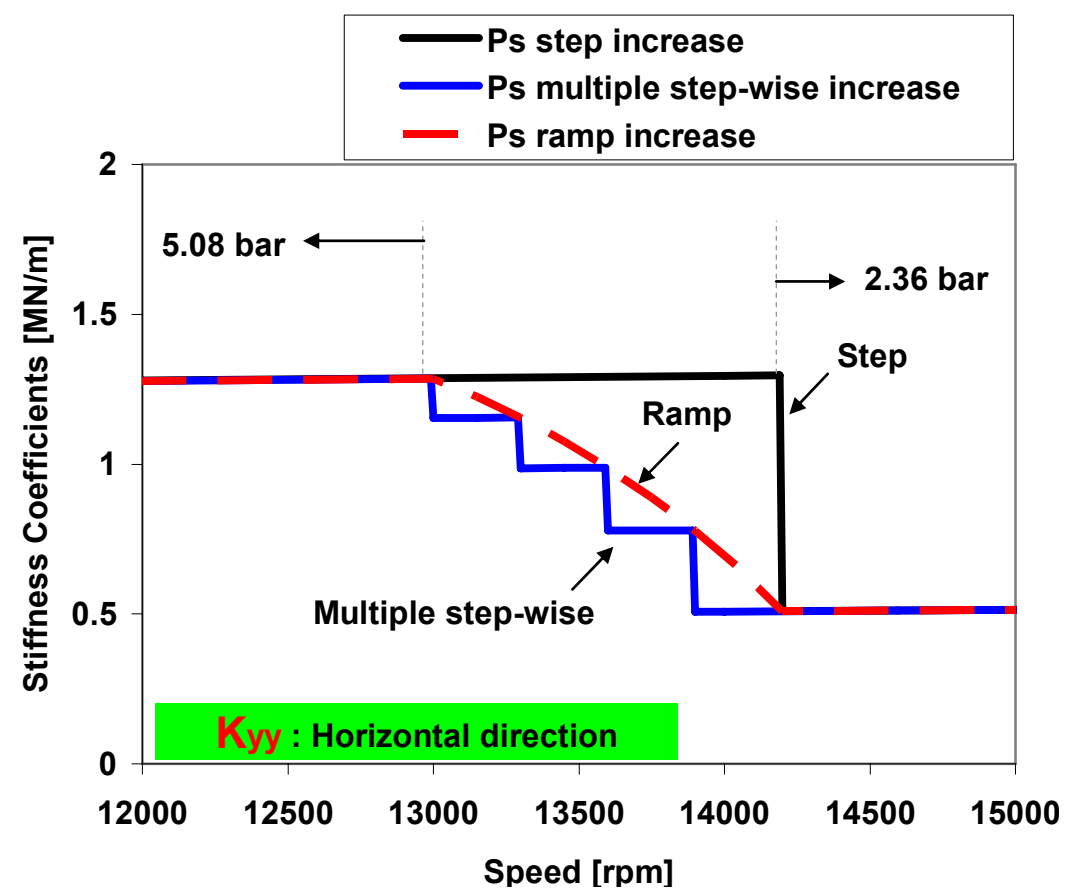

Fig. A.5 Comparison of direct stiffnesses for step jump, multiple step-wise, and ramp increase in supply pressure. Synchronous speed coefficients. Right bearing horizontal direction.

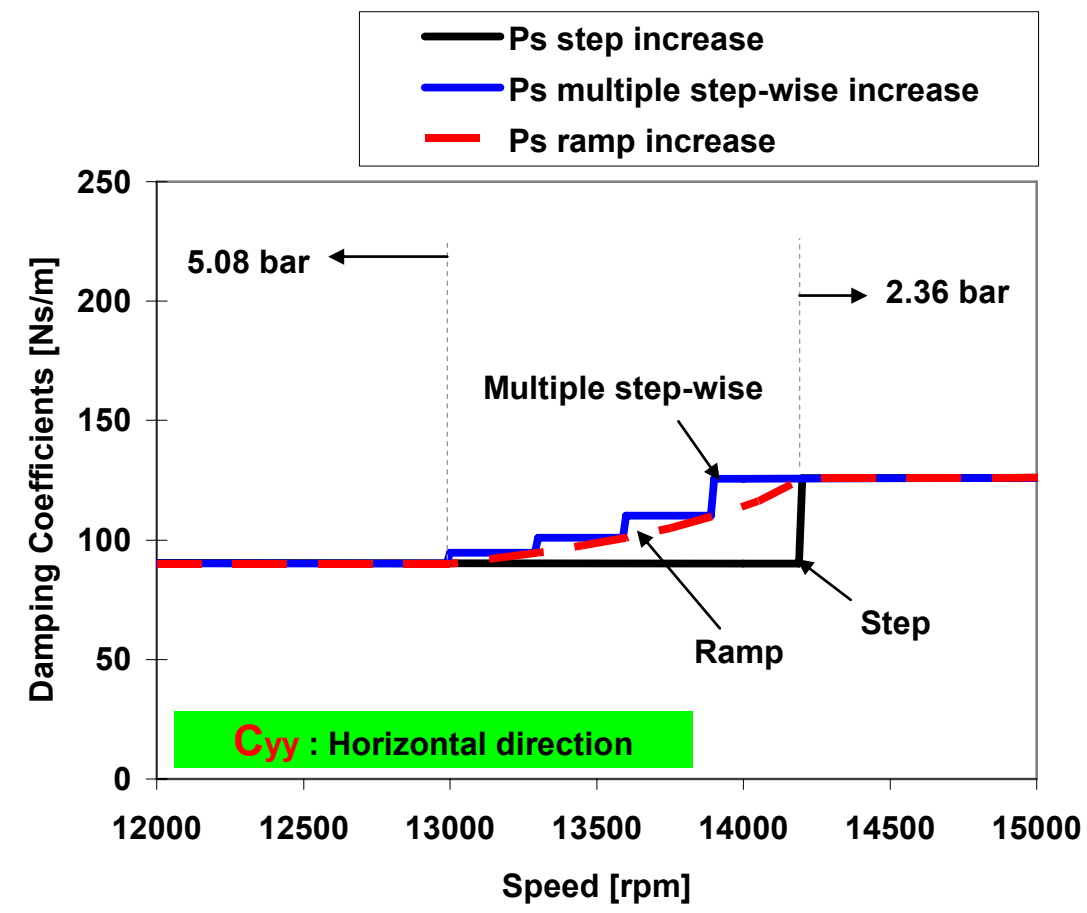

Fig. A.6 Comparison of direct damping coefficients for step jump, multiple step-wise, and ramp increase in supply pressure. Synchronous speed coefficients. 


\section{APPENDIX B SPECIFICATION OF ELECTRO-PNEUMATIC AIR REGULATOR}

Figure B.1 depicts the acquierd electro-pneumatic air regulator. This regulator controls air pressure in proportion to an input electronic signal. Table B.1 shows the specifications of the regulator. This is custom-made device manufactured by SMC Corporation. The model number is ITV2050-21N2CL4-X102. The unit costs $\$ 424$.

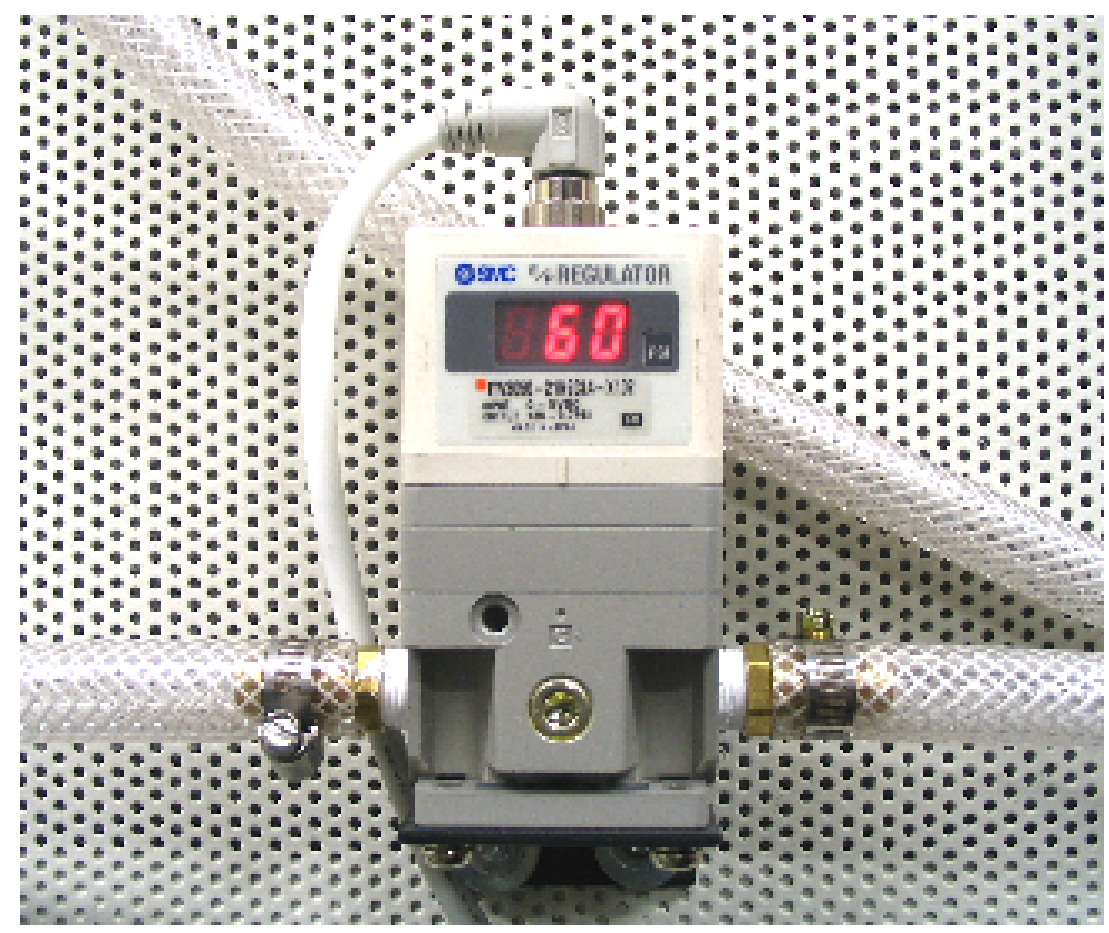

Fig. B.1 Photograph of electro-pneumatic air regulator. 
Table B.1 Main parameters of electro-pneumatic regulator

\begin{tabular}{ccc}
\hline Parameter & Value & Unit \\
\hline Power supply & 24 & Vdc \\
Regulating pressure range & $1.1 \sim 10.0$ & bar (absolute) \\
Maximum supply pressure & 11 & bar (absolute) \\
Maximum Flow rate & 1500 & L $/$ min \\
Port size & $1 / 4$ & \\
Input signal & $0 \sim 5$ & $\mathrm{kdc}$ \\
Input impedance & 6.5 & $\mathrm{Vdc}$ \\
Output signal & $1 \sim 5$ & second \\
Response time & $0.3 \sim 0.4$ & bar \\
Linearity & $\pm 1 \%$ for full scale & \\
Sensitivity & 0.02 &
\end{tabular}




\section{VITA}

Keun Ryu was born in Daegu, Korea. He received his B.S. (2003) and M.S. (2005) degrees (Mechanical Engineering) from Hanyang University, Korea.

He worked for two years (2003 2004) as a Graduated Studying Fellow at the Korea Institute of Science and Technology (KIST). This experience included developing a micro power generating device (PowerMEMS) and oil-free turbomachinery.

He joined the Turbomachinery Laboratory at Texas A\&M University since 2005. Currently, he is performing comprehensive rotordynamic tests for hybrid flexure pivot tilting pad gas bearings to advance the technology of gas bearings for applications to oilfree turbomachinery.

Permanent Mailing Address:

Keun Ryu

Woobang Chungah APT. 105-509

Bummul-dong, Suseong-gu

Daegu, Republic of Korea, 706-766

e-mail: keun.ryu@gmail.com 